\title{
DEVELOPMENT AND VALIDATION OF A CONJUGATE HEAT TRANSFER MODEL FOR THE TWO-PHASE CFD CODE NEK-2P
}

Nuclear Science and Engineering Division 


\begin{abstract}
About Argonne National Laboratory
Argonne is a U.S. Department of Energy laboratory managed by UChicago Argonne, LLC under contract DE-AC02-06CH11357. The Laboratory's main facility is outside Chicago, at 9700 South Cass Avenue, Argonne, Illinois 60439. For information about Argonne and its pioneering science and technology programs, see www.anl.gov.
\end{abstract}

\title{
DOCUMENT AVAILABILITY
}

Online Access: U.S. Department of Energy (DOE) reports produced after 1991 and a growing number of pre-1991 documents are available free via DOE's SciTech Connect (http://www.osti.gov/scitech/)

\author{
Reports not in digital format may be purchased by the public from the \\ National Technical Information Service (NTIS): \\ U.S. Department of Commerce \\ National Technical Information Service \\ 5301 Shawnee Rd \\ Alexandra, VA 22312 \\ www.ntis.gov \\ Phone: (800) 553-NTIS (6847) or (703) 605-6000 \\ Fax: (703) 605-6900 \\ Email: orders@ntis.gov \\ Reports not in digital format are available to DOE and DOE contractors from the \\ Office of Scientific and Technical Information (OSTI): \\ U.S. Department of Energy \\ Office of Scientific and Technical Information \\ P.O. Box 62 \\ Oak Ridge, TN 37831-0062 \\ www.osti.gov \\ Phone: (865) 576-8401 \\ Fax: (865) 576-5728
}

\begin{abstract}
Disclaimer
This report was prepared as an account of work sponsored by an agency of the United States Government. Neither the United States Government nor any agency thereof, nor UChicago Argonne, LLC, nor any of their employees or officers, makes any warranty, express or implied, or assumes any legal liability or responsibility for the accuracy, completeness, or usefulness of any information, apparatus, product, or process disclosed, or represents that its use would not infringe privately owned rights. Reference herein to any specific commercial product, process, or service by trade name, trademark, manufacturer, or otherwise, does not necessarily constitute or imply its endorsement, recommendation, or favoring by the United States Government or any agency thereof. The views and opinions of document authors expressed herein do not necessarily state or reflect those of the United States Government or any agency thereof, Argonne National Laboratory, or UChicago Argonne, LLC.
\end{abstract}




\section{DEVELOPMENT AND VALIDATION OF A CONJUGATE HEAT TRANSFER MODEL FOR THE TWO-PHASE CFD CODE NEK-2P}

prepared by

Prasad Vegendla, Adrian Tentner, Dillon Shaver, Aleks Obabko, Elia Merzari

Nuclear Science and Engineering Division, Argonne National Laboratory

September 2019 



\section{SUMMARY}

A project is underway to develop, verify and validate an advanced two-phase flow modeling capability for the highly-scalable, high-performance CFD code NEK5000 [1]. The goal of the project is to develop a new two-phase version of the NEK5000 code, named NEK2P, to simulate the two-phase flow and heat transfer phenomena that occur in a Boiling Water Reactor (BWR) fuel bundle under various operating conditions. The NEK-2P two-phase flow models follow the approach used for the Extended Boiling Framework (EBF) [2-3] previously developed at Argonne, but include more fundamental physical models of boiling phenomena and advanced numerical algorithms for improved computational accuracy, robustness, and computational speed.

The development of the NEK-2P two-phase solver and the implementation of the Extended Boiling Framework two-phase models were initially supported by Argonne National Laboratory (Argonne) through a Laboratory Directed Research and Development (LDRD) project during FY2014-2016. The development and validation of the two-phase models through analyses of selected two-phase boiling flow experiments was supported by the Nuclear Energy Advanced Modeling and Simulation (NEAMS) program in FY2017-2019.

This report focuses on the FY2019 development and validation of the Conjugate Heat Transfer (CHT) model for the NEK-2P Two-Phase, Computational Fluid Dynamics (CFD) code. The NEK-2P CHT model calculates the coupled behavior of the fluid and solid domains. In the fluid domain NEK-2P calculates the vapor and liquid phase temperatures, velocities and mass fractions. In the solid domain only the temperatures are calculated. The fluid and solid domains are coupled with a heat flux boundary condition at the fluid-solid interface. The heat flux and the wall temperatures at the fluid-solid interface are updated using the NEK-2P wall heat-flux partitioning model. A wall heat flux boundary condition is also applied to the exterior surface of the solid domain. The CHT model validation was illustrated through the analysis of three of the Becker Critical Heat Flux (CHF) tests. Reasonably good agreement with measured data was obtained in predicting the CHF location and post $\mathrm{CHF}$ wall temperature behavior illustrating the ability of the NEK-2P CHT model to simulate the $\mathrm{CHF}$ phenomena for a wide range of thermal-hydraulic conditions.

Apart from the CHT model development and validation, initial simulations were performed for the Virginia Tech. (VT) 3x3 bare rod bundle experiments including both cold and boiling flow simulations. 


\section{Table of Contents}

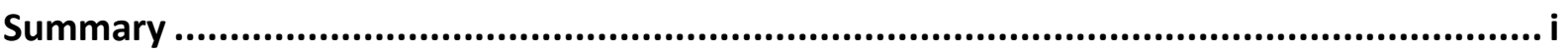

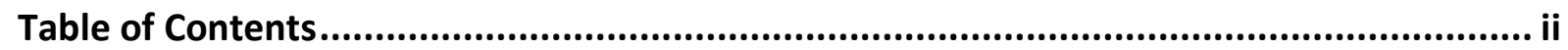

List of Figures ............................................................................................... ii

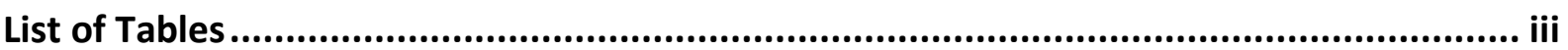

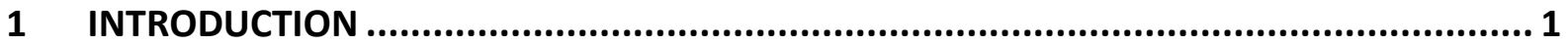

2 TWO-PHASE MODELS OF THE NEK-2P CFD CODE .............................................. 2

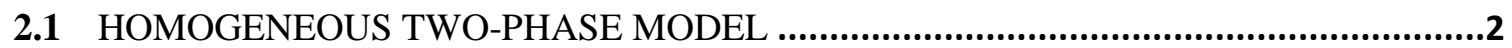

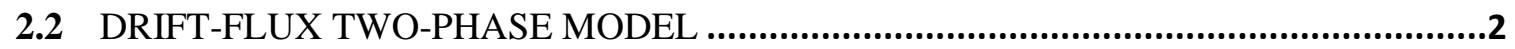

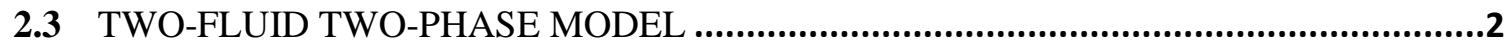

2.3.1 The Two-Fluid Two-Phase Conservation Equations …….................................................. 3

2.4 THE ADVANCED BOILING FRAMEWORK …......................................................4

2.4.1 Inter-phase Surface Topology Map and Local Flow Configuration...................................... 5

2.4.2 Inter-phase Mass, Momentum, and Energy Transfer Models .......................................... 7

2.4.3 The Wall-cell Topology ................................................................................................. 7

2.5 CLADDING-TO-COOLANT HEAT TRANSFER MODEL ......................................

3 THE NEK-2P CONJUGATE HEAT TRANSFER (CHT) MODEL .................................... 11

3.1 CHT IMPLEMENTATION IN NEK-2P …...............................................................11

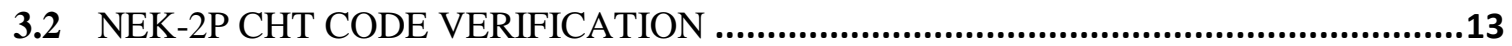

3.3 RESULTS OF NEK-2P CHT SIMULATIONS OF SELECTED BOILING FLOW

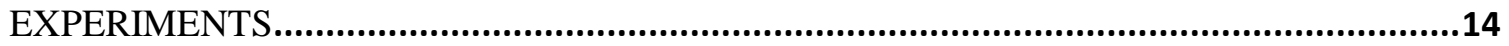

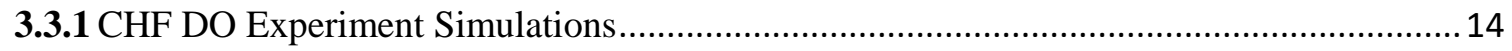

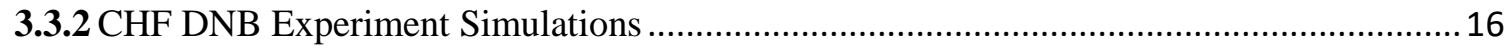

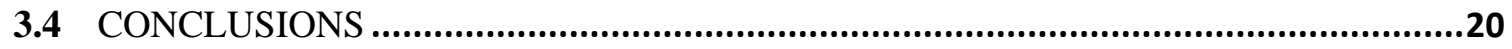

4 PRELIMINARY SIMULATIONS of VT 3x3 rod bundle .............................................. 21

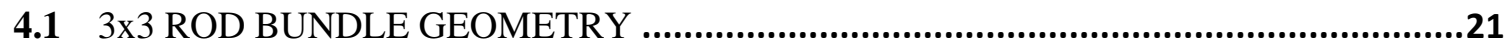

4.2 NEK-2P PRELIMINARY SIMULATION RESULTS..............................................23

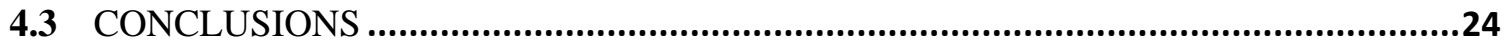

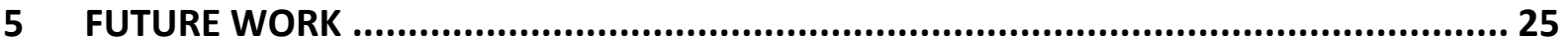

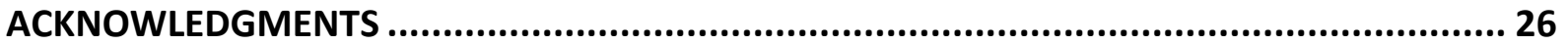

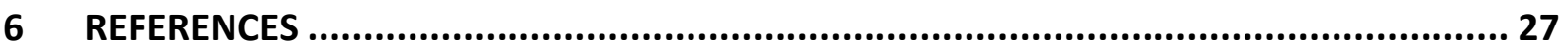




\section{LIST OF FIGURES}

Figure 1. Schematic view of upward boiling flow in vertical channel with heated walls ........ 5

Figure 2. Inter-phase surface topology map used for the advanced boiling framework ........... 6

Figure 3. General four-field inter-phase surface topology ................................................. 6

Figure 4. Wall cell general four-component topology and heat flux partition........................ 8

Figure 5. Wall cell topology and heat flux partition for lower void fraction conditions ........... 8

Figure 6. Schematic view of CHT implementation. ..................................................... 12

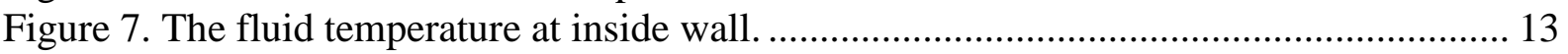

Figure 8. Schematic diagram of the Becker experiment [7] ............................................. 14

Figure 9. Contour plots for experiment C: (i) vapor volume fraction, (ii) mixture

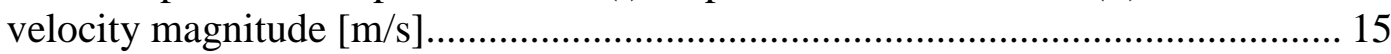

Figure 10. Wall temperatures for experiment C; (i) inside tube wall temperature and (ii) Contour plot in a vertical cross section (XZ-plane).......................................... 16

Figure 11. Contour plots for experiment G; (i) vapor volume fraction, (ii) mixture velocity magnitude $[\mathrm{m} / \mathrm{s}]$.

Figure 12. Wall temperatures $[\mathrm{K}]$ for experiment $\mathrm{G}$; (i) inside tube wall temperature and (ii) contour plot in a vertical cross section (XZ-plane).

Figure 13. Contour plots for experiment H; (i) Vapor volume fraction, (ii) Mixture velocity magnitude $[\mathrm{m} / \mathrm{s}]$.

Figure 14. Wall temperatures $[\mathrm{K}]$ for experiment $\mathrm{H}$; (i) inside tube wall temperature and (ii) contour plot in a vertical cross section (XZ-plane).

Figure 15. 3x3 rod bundle geometry [19]; (i) bottom view (ii) side view and (iii) Spacer..... 21

Figure 16. NEK-2P modeled 3x3 geometry without spacers............................................ 22

Figure 17. Contour plots over vertical slice at center of the column; (i) mixture velocity $[\mathrm{m} / \mathrm{s}]$ and (ii) Liquid temperature $[\mathrm{K}]$.................................................. 23

Figure 18. Contour plots over vertical slice at center of the column; (i) mixture velocity $[\mathrm{m} / \mathrm{s}]$, (ii) Liquid temperature $[\mathrm{K}]$ and (iii) Vapor volume fraction. 24

\section{LIST OF TABLES}

Table 1. Parameters of the CHF DO experiments analyzed with NEK-2P. ........................ 15

Table 2. Parameters of the CHF DNB experiments analyzed........................................... 17

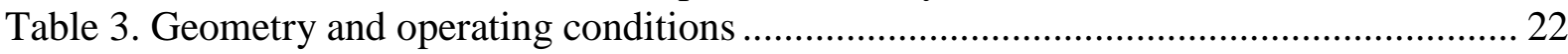





\section{INTRODUCTION}

The NEK-2P two-phase CFD code was developed at Argonne on the foundation of the highfidelity highly-scalable CFD code Nek5000 [1] which provides general high-fidelity single-phase flow modeling capabilities. NEK-2P is designed to simulate the two-phase flow and heat transfer phenomena that occur in Light Water Reactor (LWR) fuel bundles under various operating conditions. The NEK-2P two-phase flow models utilize the Extended Boiling Framework [2] methodology previously developed at Argonne, which has been extended to include more fundamental physical models of boiling flow and heat transfer phenomena and advanced numerical algorithms for improved computational accuracy and computational speed. Previous work including the initial implementation of the Extended Boiling Framework in the CFD code STAR-CD showed promising potential for the fine-mesh, detailed simulation of fuel assembly two-phase flow phenomena [3, 4, 6], including the occurrence of Critical Heat Flux (CHF) [5].

The Extended Boiling Framework (EBF) [2-5] was developed for the fine-mesh, 3dimensional simulation of the two-phase flow phenomena that occur in a Boiling Water Reactor (BWR) fuel assembly. These phenomena include coolant phase changes and multiple flow topologies that directly influence the reactor performance. The EBF boiling models, which describe the inter-phase mass, momentum, and energy transfer phenomena specific for various local flow topologies, allow the simulation of a wide spectrum of flow regimes expected in a BWR fuel assembly. An overview of these models is included below in Chapter 2. These models were ported to the high-performance high-fidelity CFD code NEK-2P to provide general twophase boiling flow modeling capabilities. The NEK-2P code was validated with multiple benchmark boiling flow tests including Becker et al. [7] and Bartolomei et al. [8]. The code predicted reasonably well the onset of dryout location and wall temperature magnitudes in multiple CHF experiments [9-11]. All previous NEK-2P simulations described the behavior of the two-phase fluid domain only, using a heat flux boundary condition at the heated-wall inner boundary. The heat transfer in the solid heated wall was not included in these simulations.

The non-uniform heat flux distribution over the cladding/coolant interfaces is ubiquitous in LWRs and other reactor types and the Conjugate Heat Transfer (CHT) model is needed to further improve the accuracy of the thermal-hydraulics simulations in coolant channels [12]. In this report, the initial implementation of a CHT model in NEK-2P is presented. The NEK-2P CHT implementation was verified initially for single-phase flow conditions. Then the CHT model was validated through multiple benchmark simulations of Becker $\mathrm{CHF}$ tests including both $\mathrm{CHF}$ under Dryout (DO) and Departure from Nucleate Boiling (DNB) conditions.

This report describes the approach adopted for the development of the NEK-2P code to allow the coupled simulation of two-phase boiling flow phenomena and conjugate heat transfer in the solid heated wall domain. Initial results of selected two-phase boiling flow experiment simulations were presented and compared with measured data.

The outline of the work is as follows. In Chapter 2 the two-phase CFD code NEK-2P was presented including the advanced boiling framework for two-phase flows. In Chapter 3, the conjugate heat transfer model and its verification and validation were presented. The preliminary results of Virginia Tech. (VT) $3 \times 3$ rod bundle boiling flows simulations were discussed in Chapter 4. Finally, future work is proposed. 


\section{TWO-PHASE MODELS OF THE NEK-2P CFD CODE}

The development of the NEK-2P has followed a staged approach, beginning with the development of a homogeneous two-phase model in FY 2014, continuing with the development of a more complex two-phase drift-flux model in FY 2015, and followed with the implementation of a two-fluid two-phase (2F-2P) model for NEK-2P in FY 2016 and FY 2017. In FY18 and FY19 additional features were developed in NEK-2P such as the Departure from Nucleate Boiling (DNB) CHF model and the Conjugate Heat Transfer (CHT) model, respectively. The initial implementation of these two-phase models has been completed and their formulation and assumptions were described below.

\subsection{HOMOGENEOUS TWO-PHASE MODEL}

Because only one velocity field is available in the Low-Mach version of NEK5000, we decided to begin with the implementation of a homogeneous two-phase model. The main assumptions of the homogeneous model were: i) the local velocities of the water and vapor phases were assumed to be the same for each computational element, and ii) the local temperatures of the water and vapor phases were assumed to be the same for each computational node. The phase transition from water to vapor was due to local enthalpy changes in a reactor fuel assembly or in a heated pipe experiment are driven by the wall heat flux. The mass, momentum, and energy conservation equations can be found in Tentner et al. [9].

\subsection{DRIFT-FLUX TWO-PHASE MODEL}

The development of the drift-flux model was an intermediate step in the development of the two-phase NEK-2P code. The approach selected by the development team was intended to extend the capabilities of the homogeneous two-phase model described above in a manner that minimizes the changes to the one-velocity two-phase solver and to provide a test-bed for the implementation of the Extended Boiling Framework while the two-velocity two-phase solver of the NEK-2P code was being developed.

The drift-flux model accounts for the effect of different vapor and liquid velocities within the framework of the one-velocity solver. The current model allows different phase velocities, but assumes that the liquid and vapor have the same temperature in each computational cell. The calculation of the local liquid and vapor velocities requires the use of the Extended Boiling Framework as described in Tentner et al. [9].

\subsection{TWO-FLUID TWO-PHASE MODEL}

The NEK-2P two-fluid two-phase model development includes two sets of transport equations for mass, momentum, and energy for water and vapor phases. The full details of the transport equations and associated closures of Extended Boiling Framework (EBF) can be found in Tentner et al. [5]. The NEK-2P two-fluid two-phase model validated for both critical heat flux and subcooled boiling flow benchmark tests [6]. 
Nek5000 [1] is a highly-scalable open-source transient CFD code developed at Argonne National Laboratory which has been awarded the Gordon Bell prize in high-performance computing and has run on over one million processors on Argonne's massively parallel Blue Gene/Q computer Mira. The code was based on the spectral element method and it was written in FORTRAN 77 and C languages. The original Nek5000 was built for the simulation of single phase constant-density flows. A later version of the code, referred to as the Low-Mach version, was modified to allow the simulation of single-phase variable-density perfect-gas flows. The Low-Mach version of Nek5000 was selected by the project team as the platform for the implementation of two-phase boiling modeling capabilities in NEK-2P. The development of NEK-2P has followed a staged approach, beginning with the development of a homogeneous two-phase model and continuing with a more complex two-phase drift-flux model. The implementation of these two-phase models was described in Tentner et al. [9]. The development of a two-fluid two-phase solver for NEK-2P and the coupling of this solver with the EBF models have later been completed. The $2 \mathrm{P}-2 \mathrm{~F}$ solver and the associated models which were used in the $\mathrm{CHF}$ experiment analyses presented in this report were reviewed below.

\subsubsection{The Two-Fluid Two-Phase Conservation Equations}

A new two-fluid two-phase solver has been implemented in NEK-2P, replacing the previous Nek5000 solver which could only track one fluid velocity field. The new NEK-2P Eulerian twofluid two-phase solver calculates time evolution of the mass, velocity, and energy of the liquid and vapor phases at all mesh locations in the computational domain by solving the mass, momentum and energy conservation equations for each phase.

The conservation of mass equation for phase $k$ is

$$
\frac{\partial}{\partial t}\left(\alpha_{k} \rho_{k}\right)+\nabla \cdot\left(\alpha_{k} \rho_{k} \boldsymbol{u}_{k}\right)=\dot{m}_{k i}-\dot{m}_{i k}
$$

The conservation of momentum equation for phase $\mathrm{k}$ is

$$
\begin{aligned}
& \frac{\partial}{\partial t}\left(\alpha_{k} \rho_{k} \boldsymbol{u}_{k}\right)+\nabla \cdot\left(\alpha_{k} \rho_{k} \boldsymbol{u}_{k} \boldsymbol{u}_{k}\right)-\nabla \cdot\left(\alpha_{k}\left(\boldsymbol{\tau}_{k}+\boldsymbol{\tau}_{k}^{t}\right)\right)= \\
& -\alpha_{k} \nabla P+\alpha_{k} \rho_{k} \boldsymbol{g}+\boldsymbol{M}
\end{aligned}
$$

The conservation of energy equation for phase $\mathrm{k}$ is

$$
\frac{\partial}{\partial t}\left(\alpha_{k} \rho_{k} e_{k}\right)+\nabla \cdot\left(\alpha_{k} \rho_{k} \boldsymbol{u}_{k} e_{k}\right)-\nabla \cdot\left(\alpha_{k} \lambda_{k} \nabla T_{k}\right)=Q
$$

The momentum equations for the two phases were coupled through the pressure, which was assumed to be the same for the two phases. The mass, momentum, and energy phase conservation equations were also coupled through the corresponding inter-phase transfer terms, which were obtained using the Extended Boiling Framework (EBF) models. 
The inter-phase forces considered in the model were: drag, turbulent dispersion, virtual mass, lift, and wall lubrication forces. In addition, inter-phase momentum transfer was associated with mass transfer hence $\boldsymbol{M}$ in Equation 2 is given by

$$
M=\boldsymbol{F}_{D}+\boldsymbol{F}_{T}+\boldsymbol{F}_{M}+\boldsymbol{F}_{L}+\boldsymbol{F}_{W L}+\dot{m}_{k i} \boldsymbol{u}_{i}-\dot{m}_{i k} \boldsymbol{u}_{k}
$$

The treatment of the inter-phase forces covers the spectrum of flow topologies expected in a BWR fuel assembly. The drag force model, for example, covers bubbles in the sub-cooled or saturated bubbly flow topology, a mixture of Taylor bubbles and smaller bubbles in the slugflow transition topology, and droplets in the droplet or mist topology. Details of the treatment of inter-phase forces can be found in Tentner et al. [10] and Ustinenko et al. [4]. The inter-phase heat transfer term $Q$ in Equation 3 was obtained by considering the heat transfer from the vapor and the liquid to the gas/liquid interface assumed to be at the saturation temperature, as described in Tentner et al. [11].

The turbulence effects were currently included through an algebraic mixing-length model. An extended $k-\omega$ model that contains extra source terms that arise from the inter-phase forces present in the momentum equations is under development.

The solution of two-fluid two-phase (2F-2P) model equations implemented in NEK-2P was based on a novel low-Mach-number numerical approach, based on previous work on reactive gaseous flow [13-14]. In this approach, the pressure was assumed to be the same for both phases. The solution method was described in detail in Tentner et al. [6].

The required phenomenological closures for the continuity, momentum and the energy equations were taken from the Extended Boiling Framework (EBF) work of Tentner et al. [2]. The Advanced Boiling Framework (ABF) included in the NEK-2P code uses a four-field twophase generalized topology representation - described below in Section 2.4 - for a more accurate prediction of interfacial area and associated mass, momentum, and energy inter-phase transfer.

\subsection{THE ADVANCED BOILING FRAMEWORK}

Inter-phase interactions in multiphase fluids depend on both the area and the topology of the phase interface. Sub-channel thermal-hydraulic codes rely on flow regime maps to evaluate the interface topology using cross-section-averaged flow parameters. CFD codes, which divide the flow space into much finer computational cells cannot rely on the traditional sub-channel flow regimes, but must evaluate instead the local topology. The ensemble of many computational cells with relatively simple topologies can provide complex global two-phase flow topologies that include all the traditional sub-channel flow regimes. The definition of the local inter-phase surface topology and the subsequent calculation of the mass, momentum, and energy inter-phase interactions was based on the use of the Extended Boiling Framework [2,9] which has been implemented in NEK-2P and was reviewed in this section. Flow topology changes typical for boiling flow in BWR fuel assemblies and the local topologies considered in the EBF were illustrated schematically in Figure 1. 


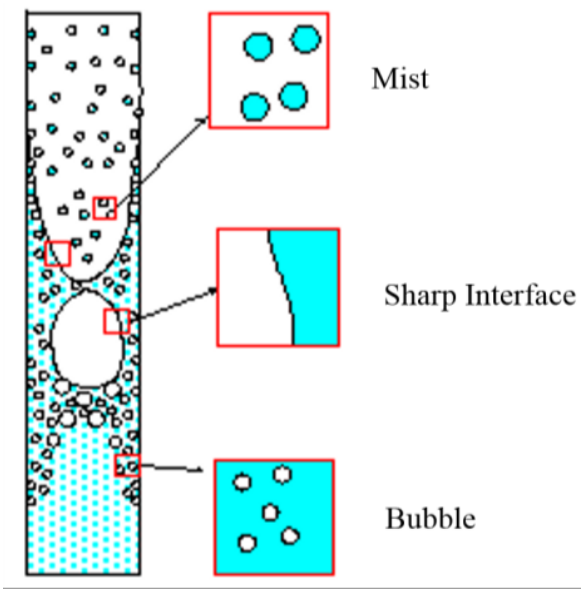

Figure 1. Schematic view of upward boiling flow in vertical channel with heated walls

While the initial EBF models were based on a two-field representation of the local topology, the NEK-2P implementation of the EBF had been extended to include a more general four-field representation of the local topology which allows a more rigorous treatment of the inter-phase interaction terms and was referred to as the Advanced Boiling Framework (ABF). A brief discussion of the new ABF features were included below. The ABF models were integrated with the new two-fluid two-phase solver.

\subsubsection{Inter-phase Surface Topology Map and Local Flow Configuration}

The EBF boiling model uses a locally calculated topology variable to allow the following topologies: a) a bubbly flow topology with spherical vapor bubbles in a continuous liquid, b) a droplet or mist topology with spherical liquid droplets flowing in a continuous vapor field, and c) a transition topology which combines the features of the two previous topologies in various proportions. The local topology was determined in this model using a local topology map based on the local void fraction. The 1-dimensional topology map used for cells that were not adjacent to solid walls was illustrated in Figure 2 together with the associated local flow topologies. The topology variable which assumes values between $0-1$ is based on the local vapor volume fraction and was then used in the code to determine the local topology and calculate the corresponding mass, momentum, and energy inter-phase transfer terms.

While the original Extended Boiling Framework (EBF) relies on a two-field representation of the local topology (liquid and vapor), the Advanced Boiling Framework recently implemented in NEK-2P introduces a more general four-field representation of the local inter-phase surface topology, illustrated in Figure 3. 


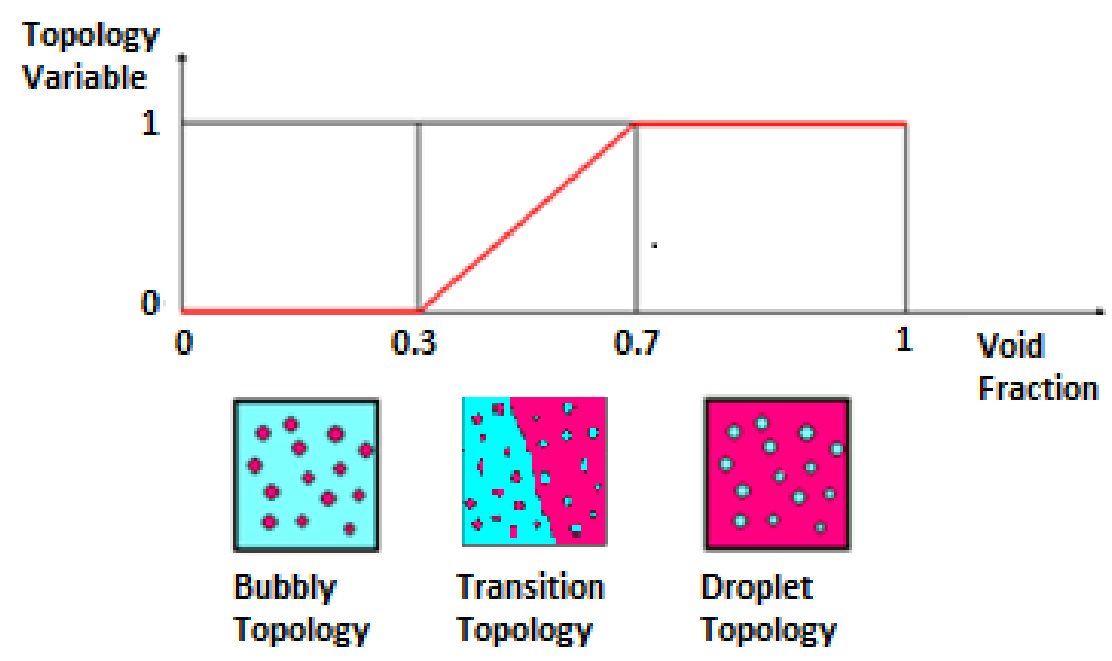

Figure 2. Inter-phase surface topology map used for the advanced boiling framework

The general four-field topology provides the foundation for the definition of local topologies in all the computational cells, but affects directly the topology in the interior transition cells and in the wall cells. In the interior cells with bubbly or droplet flow regimes only two fields were used (see Figure 2) and the ABF cell topology remains the same as the two-field EBF topology. In the interior transition topology cells and in the wall cells the use of the four-field $A B F$ topology instead of the two-field EBF topology allows a more detailed treatment of the relevant two-phase flow phenomena. The use of the four-field ABF topology in the wall cells was described in the following sections.

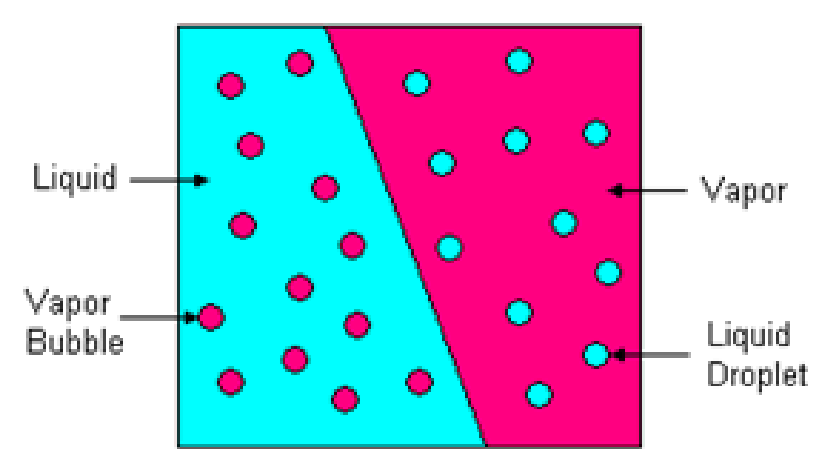

Figure 3. General four-field inter-phase surface topology 


\subsubsection{Inter-phase Mass, Momentum, and Energy Transfer Models}

The inter-phase surface topology map was used to evaluate the interfacial area and interphase interactions. Three basic local flow configurations with specific interface topology were identified (bubbly flow, mist flow and sharp interface) and the interfacial area and inter-phase mass, momentum, and energy transfer models were defined for these configurations. In the domain identified in Figure 2 as transitional topology it was assumed that a combination of basic flow configurations was present, separated by a phase interface with geometric characteristics typical of larger Taylor bubbles. Both small bubbles with a prescribed diameter and large Taylor bubbles were considered in the transition-topology cells. The diameter of the Taylor bubbles was assumed comparable to the channel hydraulic diameter. The quantities required for closure were found by determining the appropriate combination of mass, momentum, and energy exchange terms for the local flow topology. The most general transitional topology was illustrated in Figure 3, and various other transitional topologies were obtained by retaining only a sub-set of the transition master-cell features.

As demonstrated in [12], the use of the local inter-phase surface topology map allows the modeling of complex sub-channel-scale topologies that emerge from combinations of many computational cells with one of the local topologies shown in Figure 2. E.g., the typical subchannel annular flow regime illustrated in Figure 1 could be resolved into a distinct core flow region in which the gas phase was continuous and the local mist topology was used, separated by transition topology cells from a liquid film on the wall where the local bubbly topology and the wall-cell topology are used.

\subsubsection{The Wall-cell Topology}

The wall cell topology was a special case of the general cell topology discussed above. Wall cells where the local liquid volume fraction was lower than a specified value were treated in the ABF boiling model as a special liquid film and droplet topology illustrated in Figure 4 . The wall cells can contain both a liquid film and liquid droplets. As the liquid volume fraction decreases the liquid film, which initially covers the entire wall surface was assumed to become unstable and to cover the wall surface only partially. This wall cell topology was representative for conditions that can lead to the occurrence of CHF under Dryout (DO) conditions.

Because the $2 \mathrm{~F}-2 \mathrm{P}$ solver allows only one velocity and one temperature for each phase in a computational cell, the droplet and film velocities and temperatures were the same. However, the partition of the liquid between the liquid film and droplets has important implications for the heat transfer between the heated wall and the two-phase coolant. The explicit partition of liquid between the film and droplets in the wall cells allows a more detailed partition of the wall heat flux allowing an improved prediction of the $\mathrm{CHF}$ under DO conditions.

The CHF can occur under Departure from Nucleate Boiling (DNB) conditions at lower local void fractions due to high wall heat flux values. In this case the wall cell topology was simplified, with the liquid covering the entire wall area. The CHF can still occur due to the increasing number of departing vapor bubbles, which prevent or delay the re-wetting of the heated wall by the liquid, as illustrated in Figure 5. 


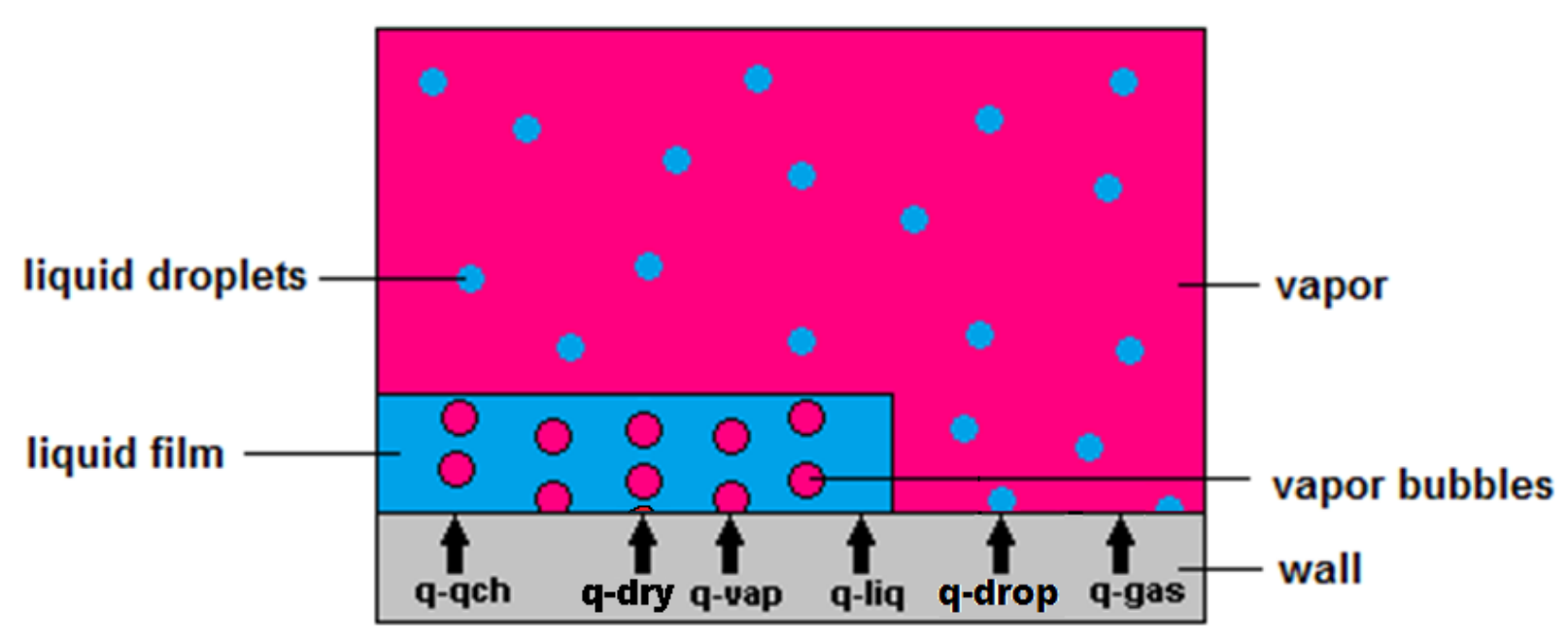

Figure 4. Wall cell general four-component topology and heat flux partition

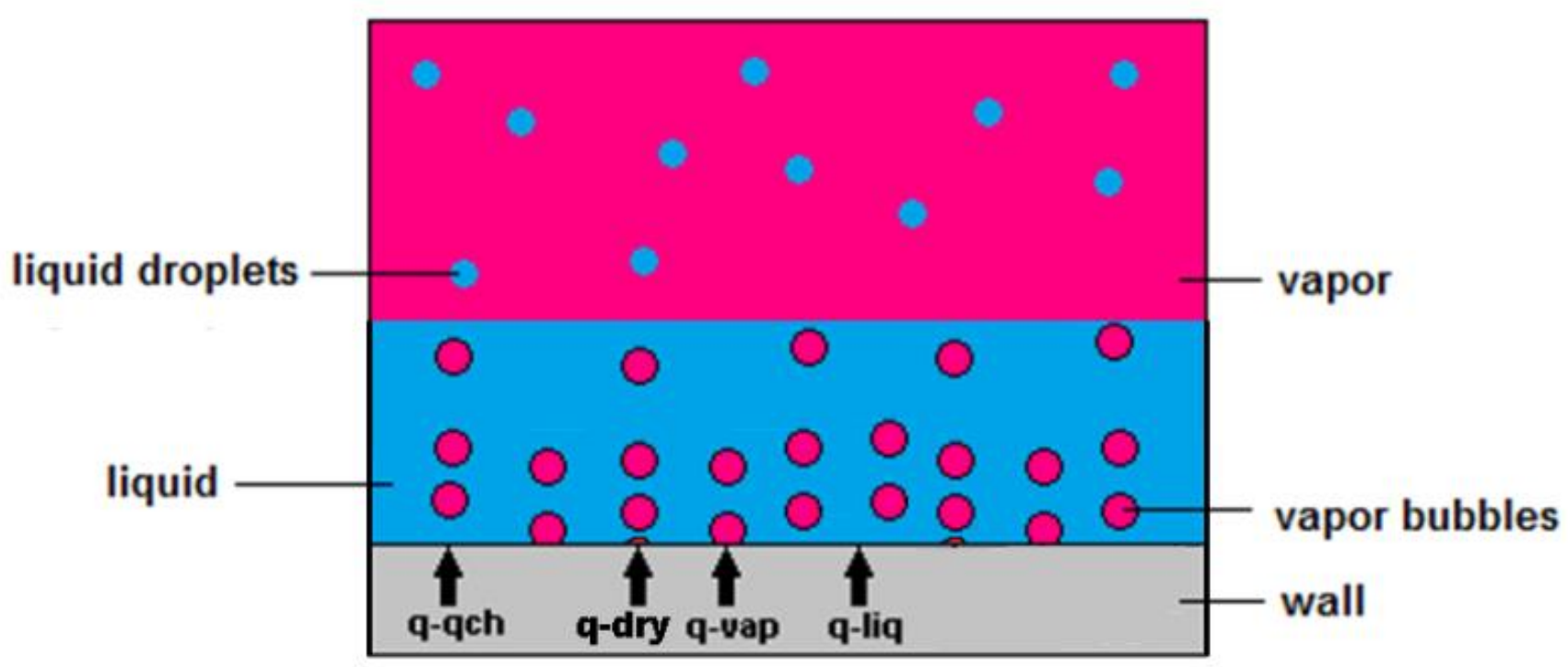

Figure 5. Wall cell topology and heat flux partition for lower void fraction conditions

\subsection{CLADDING-TO-COOLANT HEAT TRANSFER MODEL}

The calculation of the wall temperature and CHF prediction was based on partitioning of heat flux between six heat transfer components as illustrated in Figure 4. The new six-component heat flux partition replaces the previous five component partition presented in [6] and was designed to improve the modeling of the wall heat transfer phenomena which influence the CHF occurrence. 
The wall heat flux was partitioned between the following six heat transfer components illustrated in Figure 4: a) qgas, the convective heat flux from wall to the gas or vapor phase, over the wall area not covered by the liquid film; b) $q_{d r o p}$, the convective heat flux from wall to the liquid droplets, over the wall area not covered by the liquid film; c) $q_{\text {liq }}$, the convective heat flux from wall to the liquid phase, over the area covered by the liquid film but excluding the bubble nucleation area; d) $\mathrm{q}_{\text {vap }}$, the evaporation heat flux from wall to the boiling interface, over the bubble nucleation area, during the bubble growth phase of the bubble formation and departure cycle e) $q_{q}$, the quenching heat flux from the wall to the liquid over the nucleation area, during the quenching phase of the bubble formation and departure cycle, and f) qdry, the heat flux from the wall to the vapor over the nucleation area during the dry-wall phase which is assumed to follow the bubble departure and to precede the quenching phase. These heat flux components were specified per unit wall area and they decrease or become zero as the corresponding wallcontact area decreases. The wall heat flux is given by

$$
q_{w}=q_{g a s}+q_{d r o p}+q_{l i q}+q_{v a p}+q_{q c h}+q_{d r y}
$$

The heat flux components were calculated using the appropriate heat transfer coefficients and heat transfer area based on the local wall-cell topology:

$$
\begin{aligned}
& q_{\text {gas }}=h_{g} \theta_{\text {dry }}\left(1-\theta_{\text {drop }}\right)\left(T_{w}-T_{g}\right) \\
& q_{\text {drop }}=h_{d} \theta_{\text {dry }} \theta_{\text {drop }}\left(T_{w}-T_{l}\right) \\
& q_{\text {liq }}=h_{l}\left(1-\theta_{\text {dry }}\right)\left(1-\theta_{b n}\right)\left(T_{w}-T_{l}\right) \\
& q_{\text {vap }}=h_{I}\left(1-\theta_{d r y}\right) \theta_{b n} f_{\text {vap }}\left(T_{w}-T_{\text {sat }}\right) \\
& q_{\text {qch }}=h_{q}\left(1-\theta_{d r y}\right) \theta_{b n} f_{q c h}\left(T_{w}-T_{l}\right) \\
& q_{d r y}=h_{g}\left(1-\theta_{d r y}\right) \theta_{b n} f_{d r y}\left(T_{w}-T_{l}\right)
\end{aligned}
$$

where $\theta_{d r y}$ is the fraction of the total cell wall area covered by vapor, $\theta_{d r o p}$ is the fraction of the dry wall in contact with the liquid droplets, $\theta_{b n}$ is the fraction of the area covered by liquid which was covered by bubble nucleation sites, and $f_{v a p}, f_{q c h}, f_{d r y}$ are the fractions of the bubble formation and departure time cycle represented by the respective cycle phases shown in Eq. 12 .

The formulation of the previous wall heat transfer model based on partitioning the heat flux into five components $\left(q_{g a s}, q_{\text {liq }}, q_{v a p}, q_{q c h}, q_{\text {drop }}\right)$ was described in [6]. This model was referred below as the CHF DO model. The sixth component of the wall heat flux $q_{d r y}$ represents the heat transferred between the heated wall and the bubble nucleation sites during the dry-out period assumed to follow the bubble departure from the wall. It has been added in order to better represent the phenomena that affect the CHF under DNB conditions. The six-component heat flux partitioning model was referred below as the CHF DO-DNB model. In the CHF DO model the bubble formation and departure cycle was divided into two phases, the bubble growth and the quenching phase, following the Kurul-Podowski model [15]. In the new CHF DO-DNB model 
the bubble formation and departure cycle was divided into three phases: the bubble growth phase, the dry-out phase that follows the bubble departure, and the quenching phase [16].

$$
t_{B B}^{c y c l e}=t_{v a p}+t_{d r y}+t_{q c h}
$$

The length of the dry-out period $t_{\text {dry }}$ is a function of the wall superheat and under DO conditions is equal to zero or remains small, so that the six-component heat partitioning model becomes equivalent to the five-component CHF DO model. Under DNB conditions however $t_{d r y}$ becomes significant and plays an important role in the prediction of CHF DNB as illustrated in Section 3. The length of the dry-out period $t_{\text {dry }}$ is based on the value of the nucleation site density obtained from $[2,15]$

$$
n^{\prime \prime}=\left(m \Delta T_{\text {sup }}\right)^{p}
$$

where $\Delta T_{\text {sup }}=T_{\text {wall }}-T_{\text {sat }}$ is the wall superheat, $\mathrm{m}=185$ and $\mathrm{p}=1.805$ [15]. As long as the wall area occupied by the bubbles does not exceed the total liquid film area Equation 13 is used and $\mathrm{t}_{\text {dry }}=0$. If the wall superheat $\Delta T_{\text {sup }}$ exceeds $\Delta T_{d r y}$ when the wall area occupied by the bubbles exceeds the total liquid film area the nucleation site density cannot increase anymore and instead $\mathrm{t}_{\text {dry }}$ increases as a function of $\left(\Delta T_{\text {sup }}-\Delta T_{d r y}\right)$ :

$$
t_{d r y}=t_{B B, o}^{c y c l e} C\left(\delta_{f i l m}\right)\left(\frac{\Delta \mathrm{T}_{\text {sup }}}{\Delta \mathrm{T}_{d r y}}-1\right)
$$

where $t_{B B, o}^{c y c l e}$ is the length of the bubble-cycle before the occurrence of dry-out and $C\left(\delta_{f i l m}\right)$ is a coefficient that accounts for the effect of the liquid film thickness. The wall-cell topology illustrated in Figure 4 and the heat flux partitioning models described above were used the analysis of the CHF experiments described in Section 3. 


\section{THE NEK-2P CONJUGATE HEAT TRANSFER (CHT) MODEL}

\subsection{CHT IMPLEMENTATION IN NEK-2P}

The NEK-2P CFD boiling code was extended to include a Conjugate Heat Transfer (CHT) model so that the coupled thermal-hydraulic phenomena that occur in a LWR fuel bundle, including the heat conduction in the fuel and cladding, can be studied. The ability to calculate the solid fuel and cladding temperatures was important in analyses of fuel assemblies where azimuthal heat flux non-uniformities can be present or/and conduction heat transfer to assembly structures such as spacers can affect the assembly thermo-hydraulic phenomena. The CHT model was necessary for the coupling of the thermal-hydraulic models with advanced fuel and neutronic codes.

The Conjugate Heat Transfer (CHT) model allows the coupled simulation of the two-phase fluid domain and the solid heated walls. The heat transfer between the solid and fluid domains describes the exchange of thermal energy at the interfaces between them. In solids, conduction dominates whereas in fluids, convection usually dominates. The addition of the CHT model significantly expands the capabilities of the NEK-2P code to describe the behavior of complex power plant components where boiling plays an important role such as LWR fuel bundles or steam generators. In many cases, the heat flux distribution at the fluid domain boundary was not known a priori but must be calculated during the simulation. In the case of the LWR fuel pins, for example, the heat flux may exhibit azimuthal variations due to the neutron flux distribution and/or azimuthal variations in the fuel composition or geometry. The non-uniform heat generation in the fuel pins can be calculated by modern fuel codes such as BISON [17] which can be coupled with the new $\mathrm{CHT}$ model in NEK-2P to provide a more accurate distribution of the heat flux at the outer cladding surface.

The heat transfer in solids due to conduction was described by Fourier's law defining the conductive heat flux, $q^{\prime \prime}$, proportional to the temperature gradient: $q^{\prime \prime}=k \nabla T$. For the timedependent problem considered in NEK-2P the temperature field in an immobile solid verifies the following form of the heat equation

$$
\rho C_{p} \frac{\delta T}{\delta \mathrm{t}}=\nabla \cdot(k \nabla T)+q^{\prime \prime \prime}
$$

The CHT model implementation uses a special script named NEKNEK which was used to run coupled NEK-2P simulations for both fluid and solid domains. NEKNEK executes two concurrent NEK-2P simulations which use the same time step and exchange heat at the common boundary interface during each time step. The heat flux boundary condition was now specified at outer surface of the heated wall (figure 6). The NEK-2P CHT model updates the heat transfer through the pipe wall and the heat transfer to the flowing fluid using the interface heat flux partitioning models described in Section 2.5 above. 
In the fluid domain, the NEK-2P solves liquid and vapor velocities, temperatures and mass fractions for both vapor and liquid phases [9]. In the solid domain, the NEK-2P solves only for solid temperatures where the wall-heat flux boundary condition applied to exterior of the solid surface. The heat flux at the solid-fluid interface considered as a source for the fluid domain and sink for the solid domain. The source and sink heat flux terms were calculated based on the sixcomponent wall heat flux partitioning model shown in Section 2.5 above. Recently, the NEK-2P CHT implementation and its validation were presented and published in $18^{\text {th }}$ International Topical Meeting on Nuclear Reactor Thermal Hydraulics (NURETH-18) conference [18].

Heat Flux boundary conditions at the fluid-solid interface were updated each time step:

Fluid mesh: $q_{\text {fluid }}=q_{w, \text { intf }}=q_{\text {gas }}+q_{\text {drop }}+q_{\text {liq }}+q_{\text {vap }}+q_{q c h}+q_{d r y}$

Solid mesh: $q_{\text {solid }}=-q_{w, \text { intf }}$

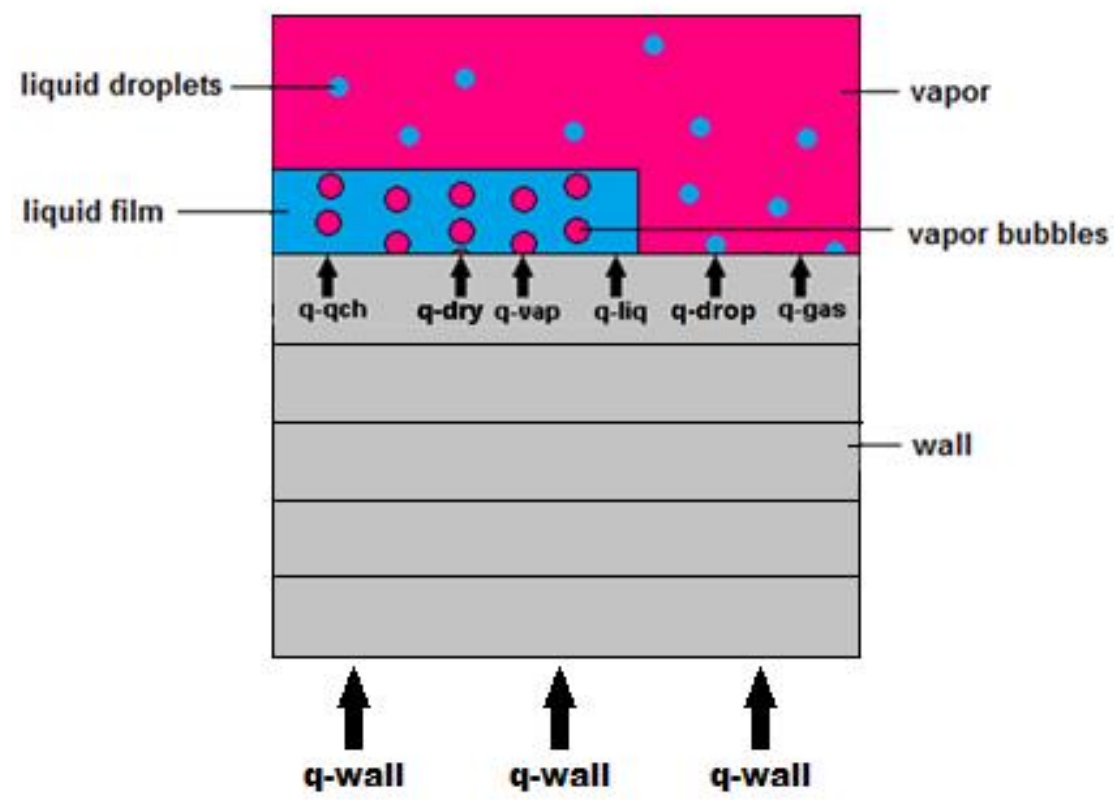

Figure 6. Schematic view of CHT implementation.

When using the NEK-2P CHT model, the heat flux $q_{w}$,int at the solid-fluid interface at a given axial and azimuthal location can be different from the heat flux $q_{\text {wall }}$ applied at the outer wall surface at the same axial and azimuthal location. This can occur due to potential axial and/or azimuthal heat flux redistribution in the solid wall. In contrast, for the no-CHT version of NEK-2P the heat flux boundary condition was applied directly at the fluid domain heated boundary. The heat flux partitioning model was still used to determine the inner wall temperature, but the heat flux redistribution in the solid domain cannot be calculated without the CHT model. The implementation of the CHT model significantly expands the NEK-2P capability to describe more accurately the behavior of LWR fuel assemblies and other applications where boiling flow interacts with solid structures with non-uniformly heated walls. 
The CHT implementation has been verified through comparison with results of single-phase flow no-CHT simulations as described in Section 3.2, and validated through simulations of twophase boiling flow CHF tests as described in Section 3.3 below.

\subsection{NEK-2P CHT CODE VERIFICATION}

The new CHT model implementation was verified with non-boiling simulations to ensure conservation of energy at the interface between the solid and fluid domains. Single-phase flow in a cylindrical tube with L/D ratio of 10 is considered. In this simulation both solid and fluid parts were solved together. The uniform wall-heat flux was applied at external solid surface. The fluidsolid fluxes at the boundary between the fluid and solid domains were updated at the end of each time step. Simulations including the fluid domain only were also performed with uniform wallheat flux boundary to verify the NEK-2P CHT implementation. In both simulations, the calculated temperatures at the inside wall surface were identical (figure 7). Furthermore, the identical temperatures were obtained in the fluid domain (not shown). It was concluded that the NEK-2P CHT implementation was correctly implemented.

The full 3D pipe volume was discretized with a total of $\sim 2.52$ million mesh points, using 700 slices in the axial direction and 2400 and 1200 points respectively in each radial cross section for fluid and solid domains. Grid sensitivity study was shown in Tentner et al. [16] for fluid domain using same set of operating conditions. In the simulations, the wall cell thickness was considered to be $63 \mu \mathrm{m}$ to capture the flow behavior near the wall.

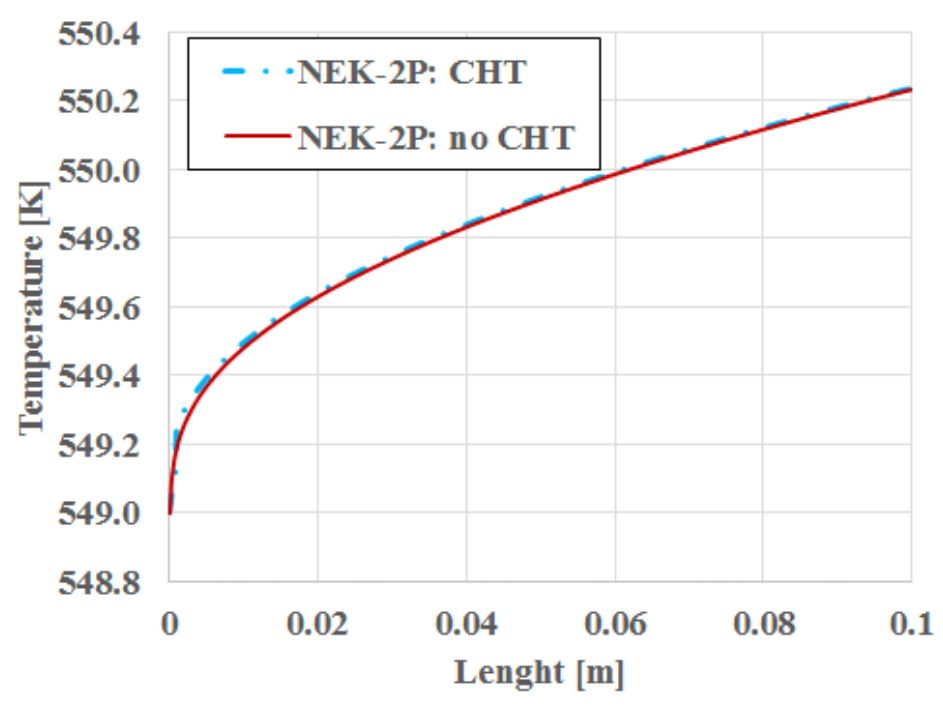

Figure 7. The fluid temperature at inside wall. 


\subsection{RESULTS OF NEK-2P CHT SIMULATIONS OF SELECTED BOILING FLOW}

\section{EXPERIMENTS}

The implementation of the CHT model in two-phase CFD code NEK-2P was validated through simulations of selected boiling flow experiments and comparison of calculated results with experimental data. The validation effort to date relies on analyses of two-phase flow experiments available in the open literature [7]. The validation effort includes the analysis of multiple boiling flow experiments addressing a wide spectrum of two-phase flow phenomena relevant for reactor fuel bundles, following the approach used previously for the validation of the EBF models implemented in the NEK-2P code $[5,6,9]$.

\subsubsection{CHF DO Experiment Simulations}

In this section, the NEK-2P CHT model was used to analyze a two-phase flow CHF experiment performed by Becker et al. [7] under DO conditions. Analyses of six CHF DO experiments (table 1) were previously performed with NEK-2P prior to the implementation of the CHT model and the results were presented in [18]. The analysis of experiment $\mathrm{C}$ (highlighted in Table 1) was used to evaluate the performance of the CHT model used in conjunction with the NEK-2P Advanced Boiling Framework (ABF). The Becker boiling flow experiments were CHF experiments performed in a vertical heated tube as shown in Figure 8. The inner and outer diameter and length of the vertical pipe are $14 \mathrm{~mm}, 10 \mathrm{~mm}$ and $7 \mathrm{~m}$, respectively.

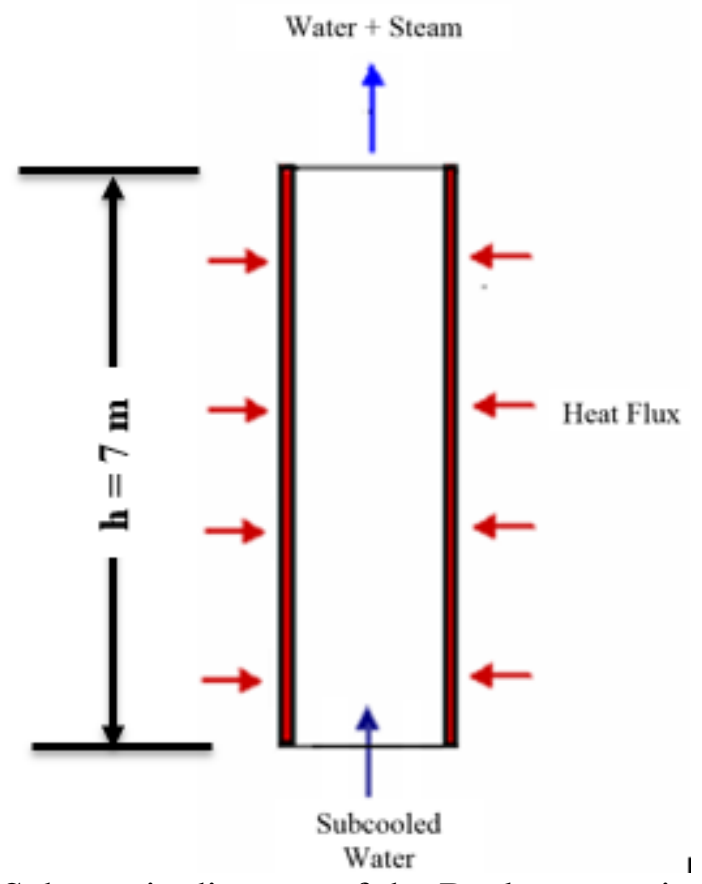

Figure 8. Schematic diagram of the Becker experiment [7]. 
Table 1. Parameters of the CHF DO experiments analyzed with NEK-2P.

\begin{tabular}{|c|c|c|c|c|c|}
\hline Exp & $\begin{array}{c}G \\
{\left[\mathrm{~kg} / \mathrm{s}-\mathrm{m}^{2}\right]}\end{array}$ & $\begin{array}{c}\mathrm{q}_{\mathrm{w}} \\
{\left[\mathrm{W} / \mathrm{m}^{2}\right]}\end{array}$ & $\begin{array}{c}\mathrm{T}_{\text {in }}-\mathrm{T}_{\text {sat }} \\
{[\mathrm{K}]}\end{array}$ & $\begin{array}{c}\mathrm{q}_{\mathrm{w}} / \mathrm{G} \\
{[\mathrm{J} / \mathrm{kg}]}\end{array}$ & $\begin{array}{c}\text { Pressure } \\
{[\mathrm{bar}]}\end{array}$ \\
\hline A & 497.0 & $35.0 \mathrm{e} 4$ & -10.3 & 704 & 70 \\
B & 1009.6 & $40.1 \mathrm{e} 4$ & -10.3 & 397 & 70 \\
C & 1008.9 & $49.9 \mathrm{E} 4$ & -10.3 & 495 & 70 \\
D & 1495.0 & $79.7 \mathrm{E} 4$ & -10.3 & 533 & 70 \\
E & 1994.9 & $79.6 \mathrm{E} 4$ & -10.3 & 399 & 70 \\
F & 2482.9 & $80.0 \mathrm{e} 4$ & -10.3 & 322 & 70 \\
\hline
\end{tabular}

The calculated void fraction distribution for the experiment $\mathrm{C}$ analyzed with NEK-2P and the CHT model was shown in Figure 9(i). The characteristic sub-channel flow regimes in a pipe with heated walls were simulated. Since the inlet temperature was only $10.3 \mathrm{~K}$ below saturation the bubbly flow regime was limited to the near-inlet region of the pipe. The annular-mist flow regime with annular liquid films on pipe wall and the mist flow regime were clearly observed in numerical simulations. The velocity rise of the two-phase mixture, due to phase change, was observed in Figure 9(ii).

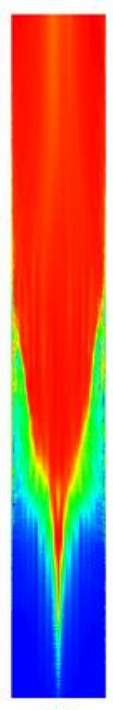

(i)

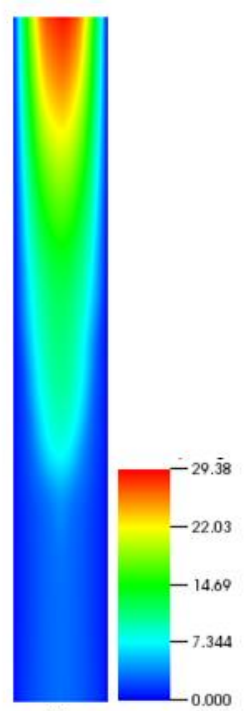

(ii)

Figure 9. Contour plots for experiment C: (i) vapor volume fraction, (ii) mixture velocity magnitude $[\mathrm{m} / \mathrm{s}]$ 


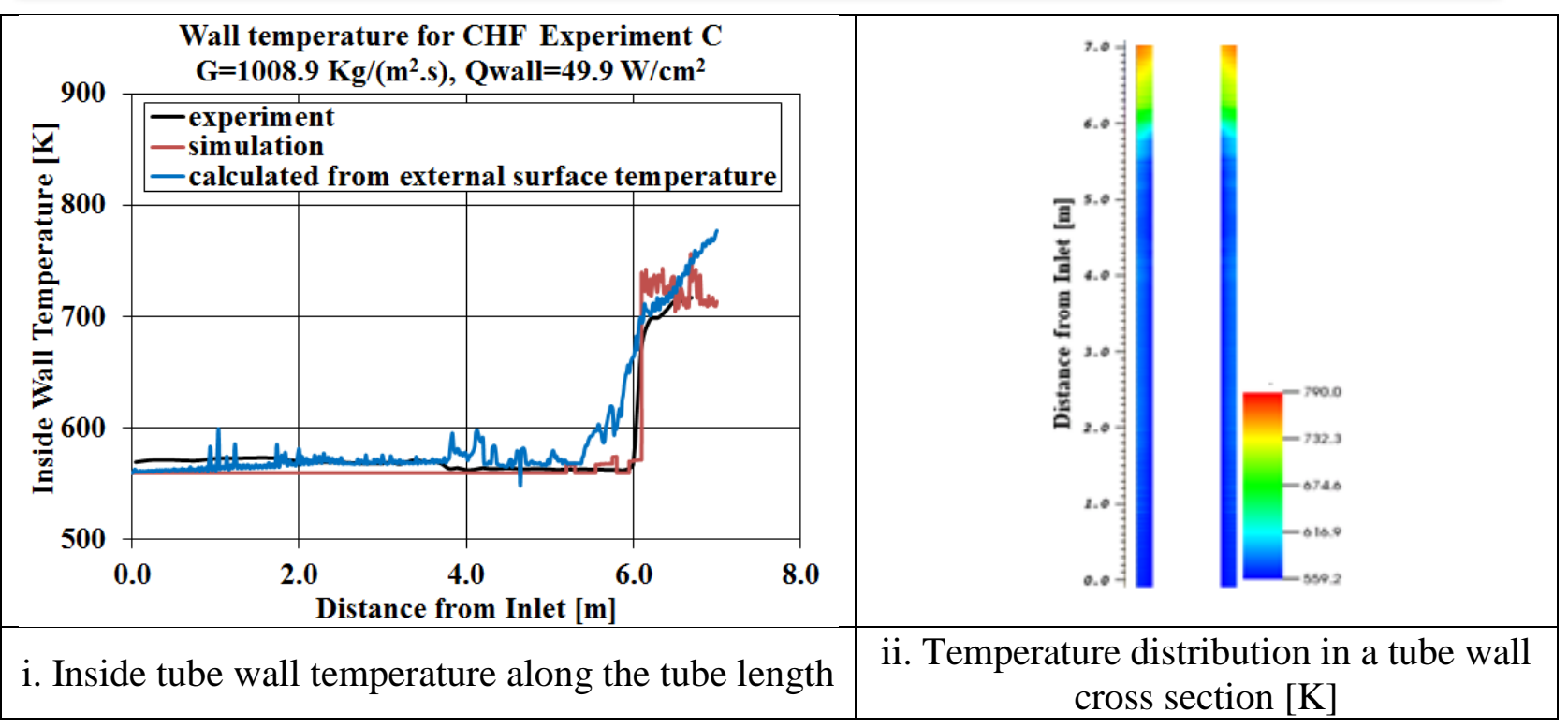

Figure 10. Wall temperatures for experiment C; (i) inside tube wall temperature and (ii) Contour plot in a vertical cross section (XZ-plane).

The calculated wall temperature as a function of the distance from the pipe inlet was shown in Figure 10(i). The inside wall temperature calculated with the NEK-2P solver was compared with the corresponding measured data. The location of the calculated sharp rise in the wall temperature agrees fairly well with the location of the measured wall temperature rise (figure 10(i)). The calculated sharp rise in the wall temperature coincides with the disappearance of the calculated liquid film on the pipe wall (figure 9(i)). Both the magnitude of the calculated wall temperature rise and the general shape of the wall temperature distribution in the post-dryout region were similar to the corresponding measured values. Also shown in Figure 10(i) (blue line) was the inside wall temperature hand-calculated from the outside wall surface temperature predicted by the NEK-2P CHT model. This curve provides an improved description of the actual experiment, taking advantage of the new CHT model. In the Becker CHF experiments only the outer wall temperature was measured, and the inner wall temperature was calculated from the outer wall temperature assuming that only radial heat transport through the pipe wall occurs, neglecting any axial heat transfer in the solid wall. As shown in Figure 10(i) using the new CHT model to reproduce this procedure using the simulation results provides an improved agreement of the post-CHF calculated wall temperature with the experimental results.

\subsubsection{CHF DNB Experiment Simulations}

NEK-2P simulations including the CHT model were also performed for two different Becker CHF benchmark tests conducted under DNB conditions, which were highlighted in Table 2. All these simulations were performed at operating pressure of 200 bar. In our previous work, only fluid domain simulations were presented [14] with the NEK-2P for the CHF DNB experiments shown in Table 2. 
Table 2. Parameters of the CHF DNB experiments analyzed.

\begin{tabular}{|c|c|c|c|c|c|}
\hline Exp. & $\begin{array}{c}G \\
{[\mathrm{~kg} / \mathrm{s}-} \\
\left.\mathrm{m}^{2}\right]\end{array}$ & $\begin{array}{c}\mathrm{q}_{\mathrm{w}} \\
{\left[\mathrm{W} / \mathrm{m}^{2}\right.} \\
]\end{array}$ & $\begin{array}{c}\mathrm{T}_{\mathrm{in}^{-}} \\
\mathrm{T}_{\mathrm{sat}} \\
{[\mathrm{K}]}\end{array}$ & $\begin{array}{c}\mathrm{q}_{\mathrm{w}} / \mathrm{G} \\
{[\mathrm{J} / \mathrm{kg}]}\end{array}$ & $\begin{array}{c}\text { Pressur } \\
\mathrm{e}[\mathrm{bar}]\end{array}$ \\
\hline $\mathrm{G}$ & 1507.4 & $59.8 \mathrm{e} 4$ & -10 & 396 & 200 \\
$\mathrm{H}$ & 1013.1 & $39.6 \mathrm{e} 4$ & -10 & 390 & 200 \\
$\mathrm{I}$ & 1017.0 & $29.7 \mathrm{e} 4$ & -10 & 292 & 200 \\
\hline
\end{tabular}

The contour plots for vapor volume fraction and mixture velocity in a vertical cross section through the heated fluid domain were shown in Figure 11. The observed vapor volume fractions rise significantly near the wall due to wall heat addition. The significant rise of velocity towards an outlet was due to fluid acceleration because of the vapor formation which has a lower density than the liquid phase. The calculated void fraction distribution shows a diminishing central region with subcooled liquid or lower void-fraction that extends to the pipe outlet and a growing dry vapor region near the heated pipe wall (figure 11(i)).
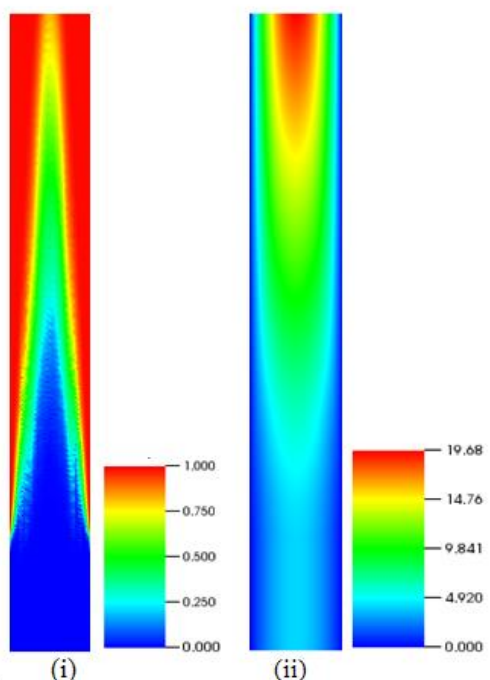

Figure 11. Contour plots for experiment G; (i) vapor volume fraction, (ii) mixture velocity magnitude $[\mathrm{m} / \mathrm{s}]$ 


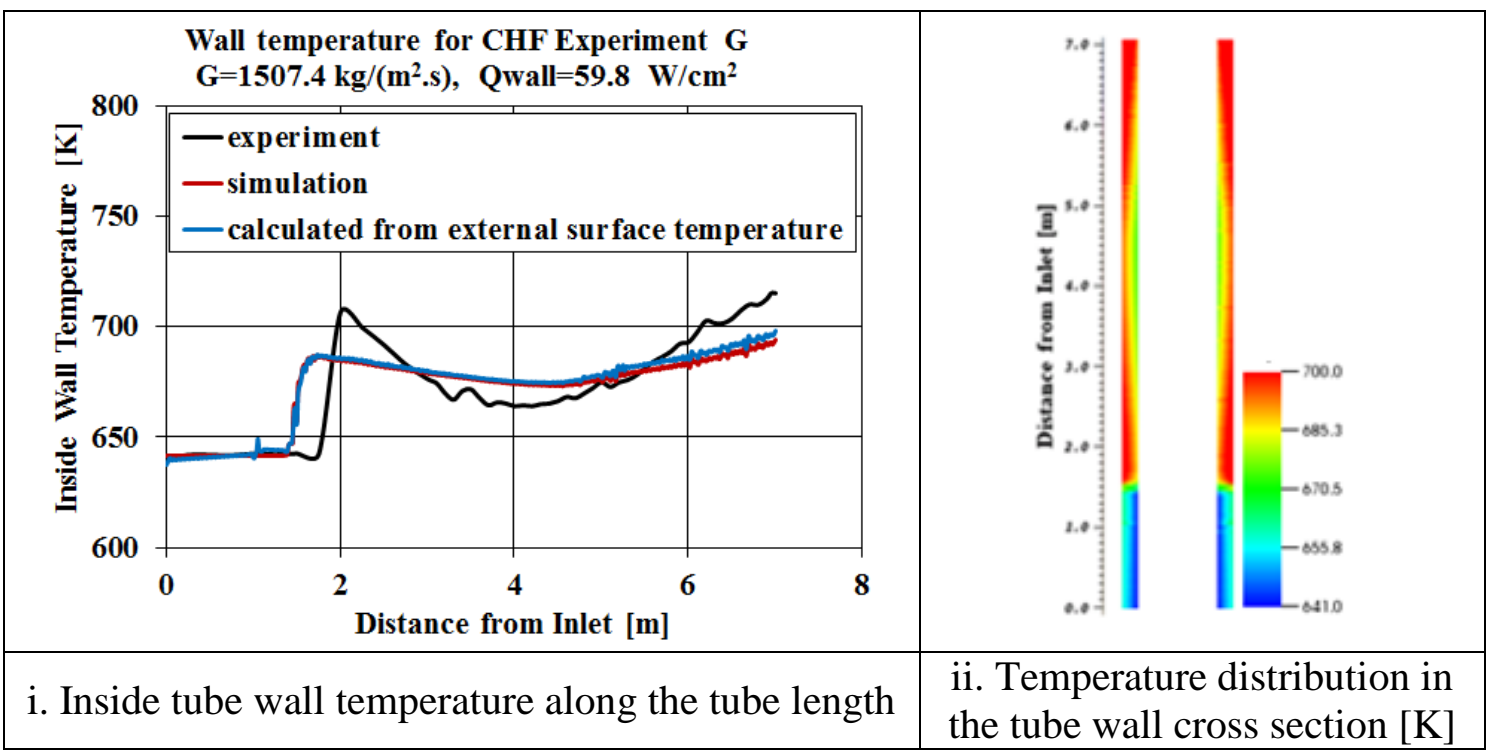

Figure 12. Wall temperatures $[\mathrm{K}]$ for experiment $\mathrm{G}$; (i) inside tube wall temperature and (ii) contour plot in a vertical cross section (XZ-plane).

The calculated and observed inside wall temperatures were shown in Figure 12(i) for experiment G. The observed onset of DNB location and wall temperature increase agree reasonably well with the experimental data. The calculated post-DNB wall temperatures show an initial decrease followed by an increase in the second half of the heated pipe, but the calculated wall temperature changes were smaller than the experimentally observed changes. Similar trends were observed in the results obtained prior to the implementation of the CHT model. Further refining of the CHF DNB model is planned in order to capture more accurately the post-DNB wall temperatures behavior. Also shown in Figure 12(i) (blue line) was the inside wall temperature hand-calculated from the outside wall surface temperature predicted by the NEK-2P CHT model. These results were very close to the inside wall temperatures calculated directly by NEK-2P (red line).

The contour plots for vapor volume fraction and mixture velocity in a vertical cross section through the heated fluid domain were shown in Figure 13 for experiment H. The observations made above for experiment $\mathrm{G}$ regarding the vapor and mixture velocity fields apply also to experiment $\mathrm{H}$. 


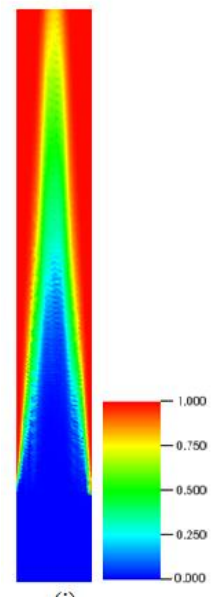

(i)

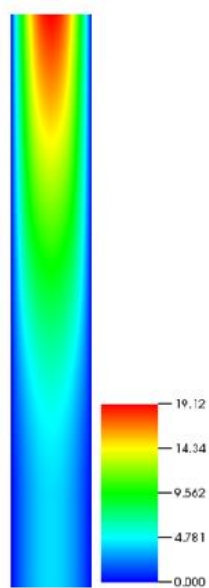

(ii)

Figure 13. Contour plots for experiment H; (i) Vapor volume fraction, (ii) Mixture velocity magnitude $[\mathrm{m} / \mathrm{s}]$.

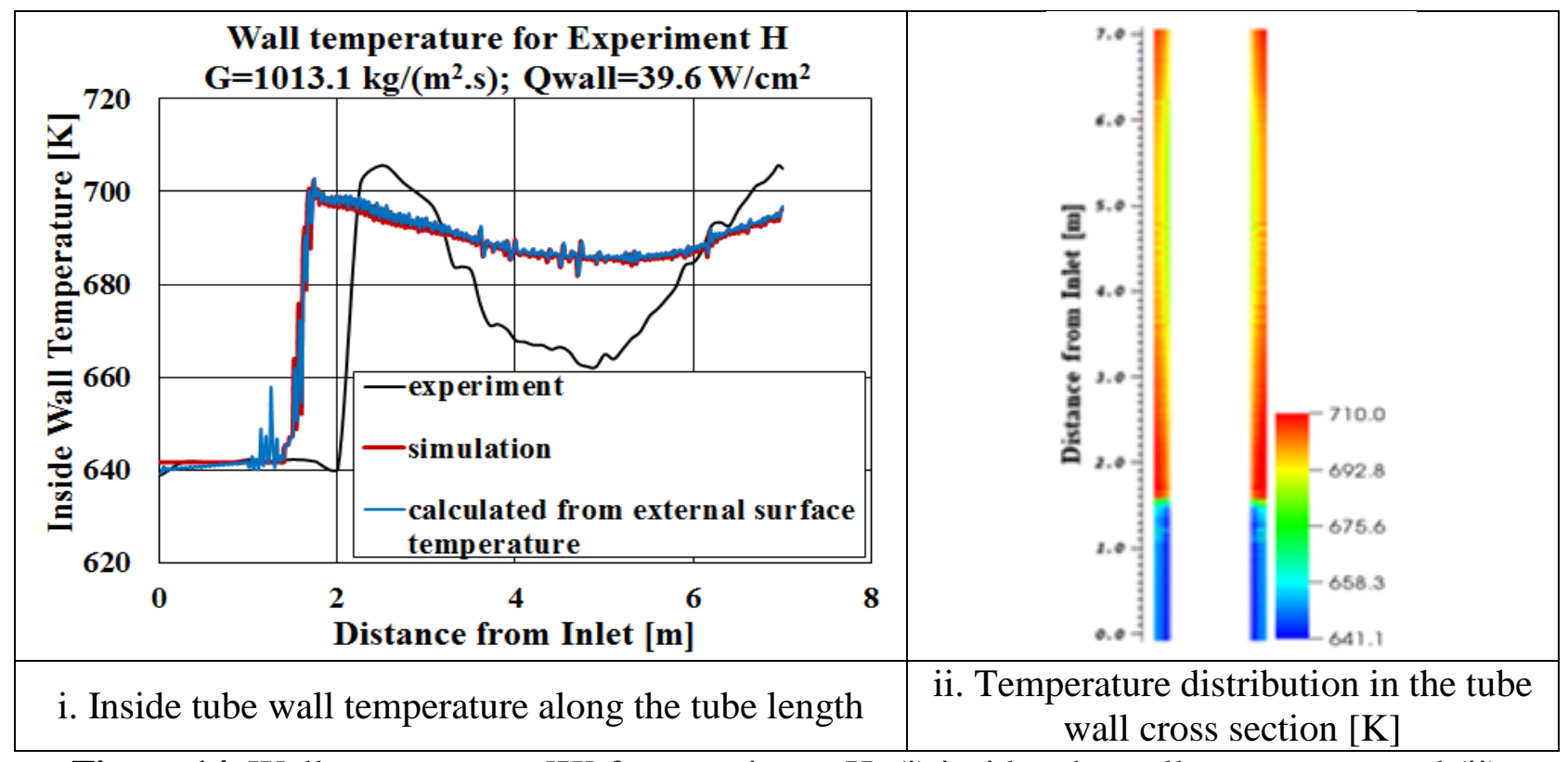

Figure 14. Wall temperatures $[\mathrm{K}]$ for experiment $\mathrm{H}$; (i) inside tube wall temperature and (ii) contour plot in a vertical cross section (XZ-plane).

The calculated and observed inside wall temperatures for experiment $\mathrm{H}$ were shown in Figure 14(i). The observed wall temperatures and onset of DNB location agree qualitatively with the experimental data similar to experiment $\mathrm{G}$. The peak wall temperature agrees reasonably well with the experiment data. The post DNB wall temperature initial decrease followed by an increase was agrees with the trend observed experimentally, but the magnitude of the wall temperature decrease was not captured. Further refining of the CHF DNB model is planned to capture more accurately the post-DNB wall temperatures behavior. Also shown in Figure 14(i) (blue line) was the inside wall temperature hand-calculated from the outside wall surface 
temperature predicted by the NEK-2P CHT model. These results were very close to the inside wall temperatures calculated directly by NEK-2P (red line).

\subsection{CONCLUSIONS}

The conjugate heat transfer model was developed and implemented in NEK-2P. This model allows the coupled simulation of the solid domain and two-phase fluid domain, allowing the specification of realistic boundary conditions. The ability to calculate the solid fuel and cladding temperatures is important in analyses of fuel assemblies where azimuthal heat flux nonuniformities and heat transfer to assembly structures such as spacers can be present and affect the thermo-hydraulic phenomena in the assembly. The CHT model is also necessary for the coupling of the thermal-hydraulic models with advanced fuel and neutronic codes.

The CHT implementation was verified first with non-boiling simulations. The predicted temperatures in the fluid domain were shown to be identical in simulations with or without CHT model. The CHT model was then validated through simulations of three Becker benchmark CHF tests performed under both DO and DNB boiling conditions. Reasonably good agreement was obtained between calculated wall temperatures and corresponding experimental data. 


\section{PRELIMINARY SIMULATIONS of VT 3×3 rod bundle}

\subsection{3x3 ROD BUNDLE GEOMETRY}

The $3 \times 3$ rod bundle has nine $(3 \times 3)$ electric heaters with diameter of $15.9 \mathrm{~mm}$, pitch: $21 \mathrm{~mm}$ [19]. The power can operate up to $14 \mathrm{KW}$ for each rod, $126 \mathrm{~kW}$ total. The maximum designed operating pressure and temperature are upto 10 bar and $180 \mathrm{C}$, respectively. The $3 \times 3$ rod bundle geometry includes two spacer grids with mixing vanes designed by Westinghouse. For visualization and optical measurements, eight large windows were included. The $3 \times 3$ rod bundle geometry and the spacer geometry are shown in Figure 15.

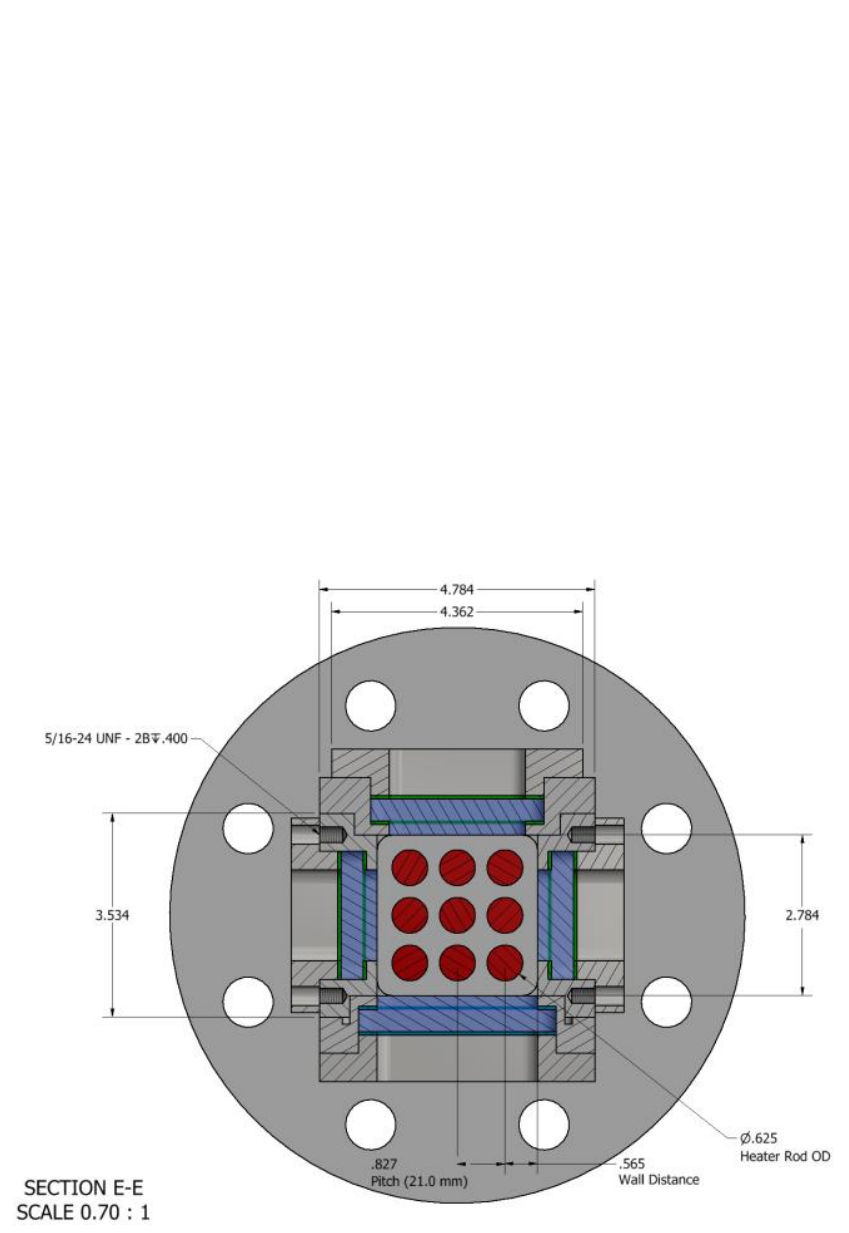

(i)

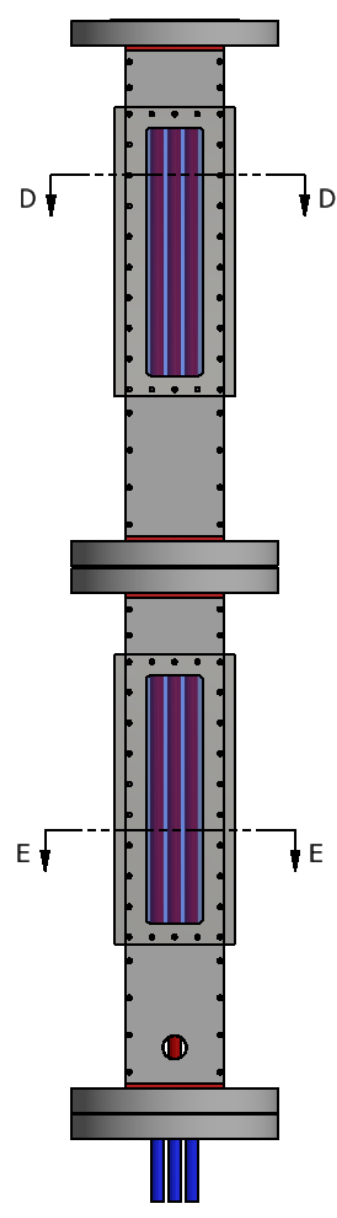

(ii)

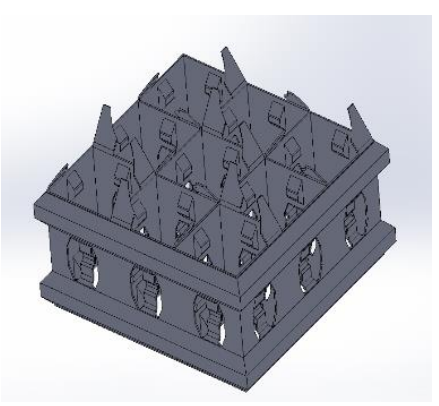

(iii)

Figure 15. 3x3 rod bundle geometry [19]; (i) bottom view (ii) side view and (iii) Spacer.

The initial NEK-2P fluid simulations were performed for simplified geometry (without spacers) as shown in Figure 16. In Table 3, the operating and boundary conditions are shown. 


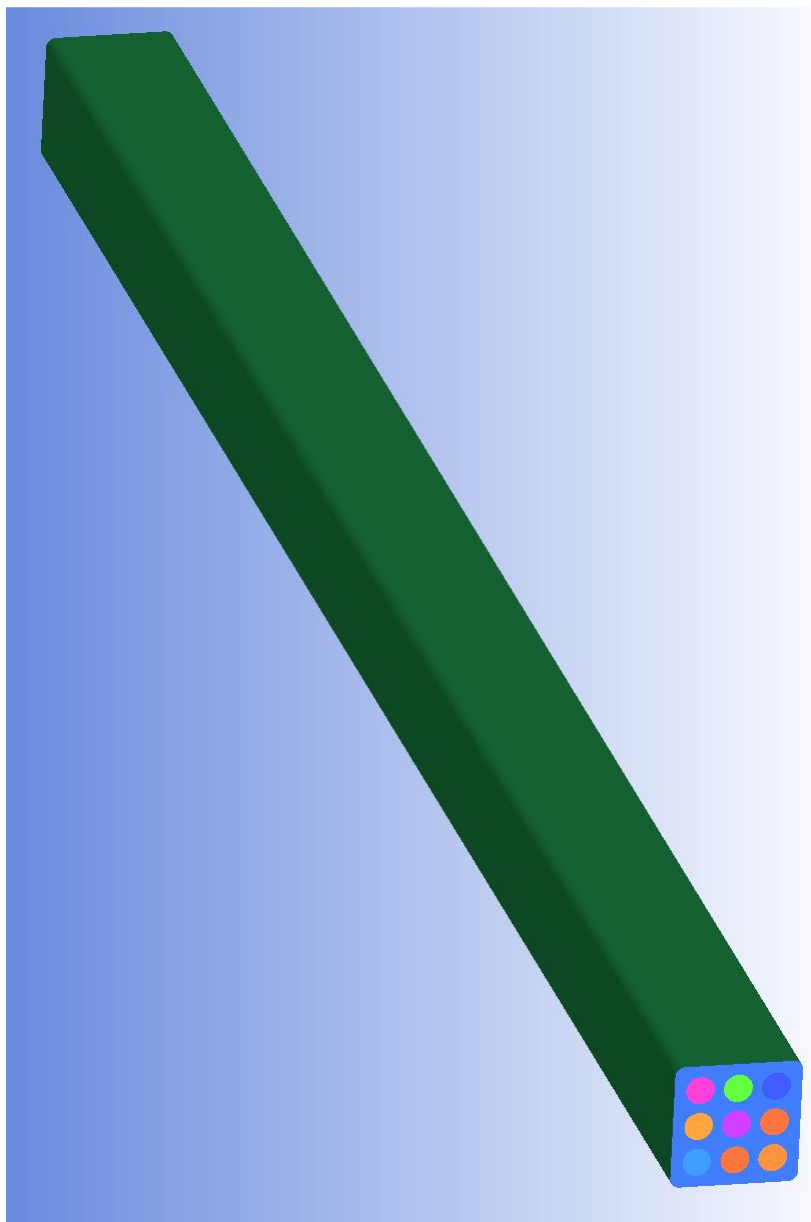

Figure 16. NEK-2P modeled $3 \times 3$ geometry without spacers.

Table 3. Geometry and operating conditions

\begin{tabular}{|c|c|}
\hline & Units \\
\hline Inlet Velocity [m/s] & 1.33 \\
Inlet Temperature [K] & 549 \\
Saturation Temperature [K] & 559 \\
Wall-heat flux [W/cm2] & 20 and 40 \\
Heated rod diameter [mm] & 15.9 \\
Heated rod Length [m] & 1.37 \\
Pitch btw heated rods [mm] & 21 \\
Duct width or depth [m] & 0.7530 \\
\hline
\end{tabular}




\subsection{NEK-2P PRELIMINARY SIMULATION RESULTS}

In Figure 17, the increased liquid phase temperatures towards an outlet were mainly due to an applied constant heat flux at fluid-solid boundary. To be noted, only fluid domain was solved using NEK-2P code. The maximum observed liquid phase temperatures were less than the fluid saturation temperature. Hence, the vapor formation was not observed for a provided wall heat flux of $20 \mathrm{~W} / \mathrm{cm}^{2}$.

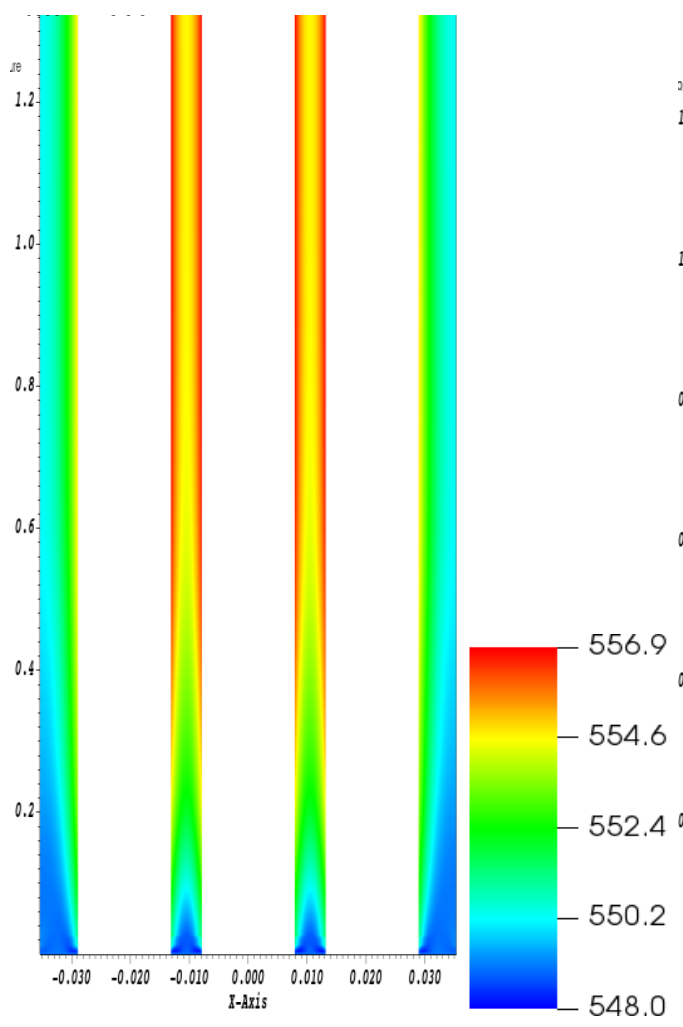

(i)

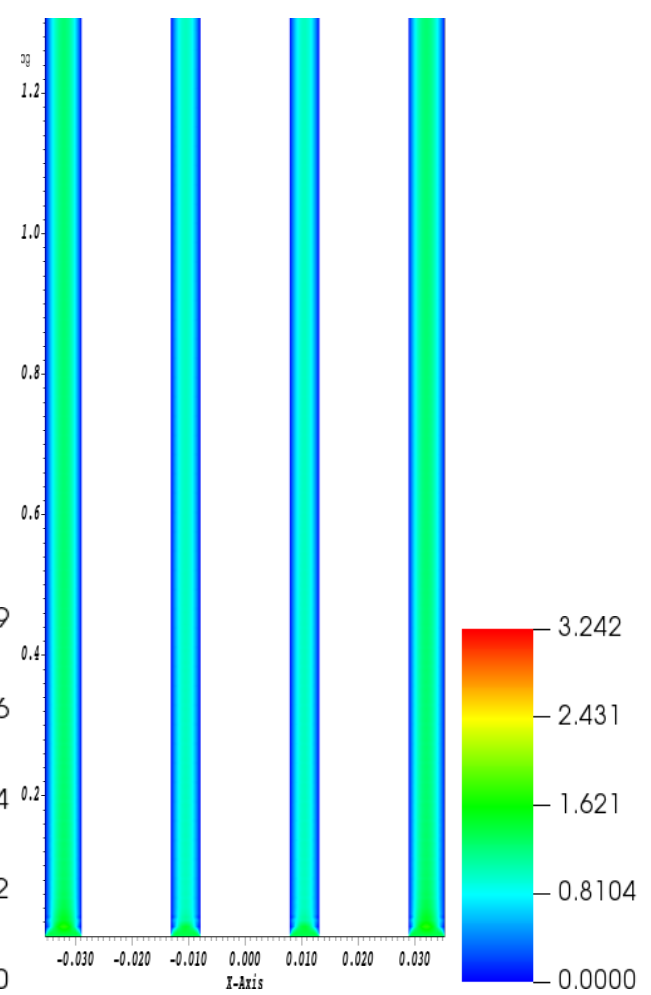

(ii)

Figure 17. Contour plots over vertical slice at center of the column; (i) mixture velocity [m/s] and (ii) Liquid temperature [K] 


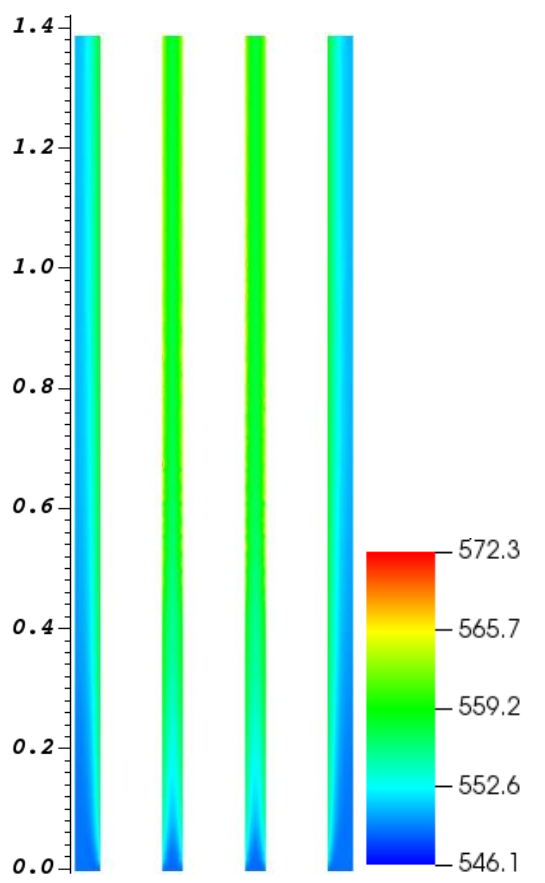

(i)

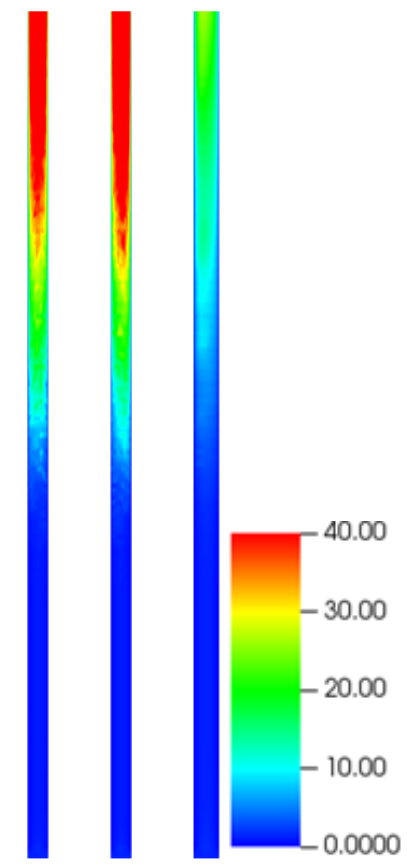

(ii)

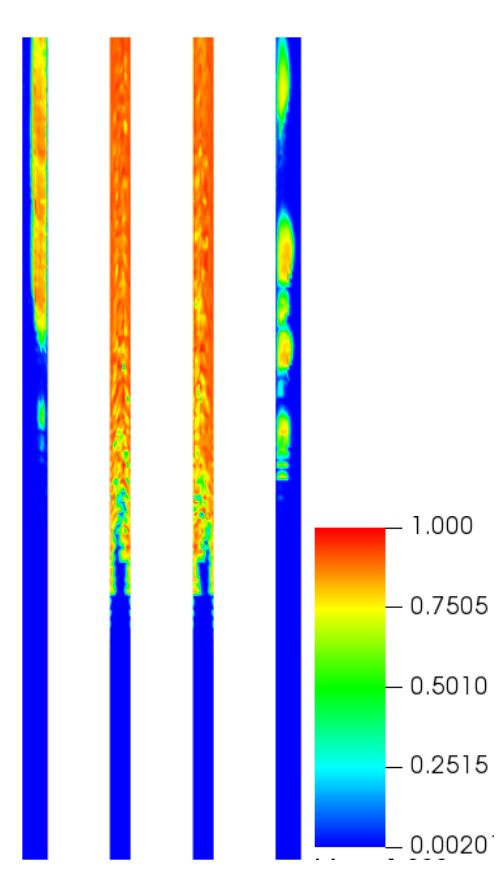

(iii)

Figure 18. Contour plots over vertical slice at center of the column; (i) mixture velocity [m/s],

(ii) Liquid temperature $[\mathrm{K}]$ and (iii) Vapor volume fraction.

From Figure 18, the increased liquid phase temperatures towards an outlet were mainly due to an applied constant heat flux at fluid-solid boundary, as discussed above in Figure 17. The vapor formation increases with an increase of axial height for a given wall heat flux of 40 $\mathrm{W} / \mathrm{cm}^{2}$. The disappearance of liquid was observed towards an outlet.

\subsection{CONCLUSIONS}

The initial simulations were performed for VT $3 \times 3$ rod bundle using NEK-2P. The significant vapor formation was observed for wall heat flux of $40 \mathrm{~W} / \mathrm{cm}^{2}$. Towards an outlet, the predicted higher fluid velocities were mainly due to vapor formation. 


\section{FUTURE WORK}

NEK-2P development and validation continues in FY20 with a focus on CHF models enhancement and simulation of both DO and DNB experiments. Continued development and validation of the NEK-2P conjugate heat transfer capability with a focus on rod-bundle simulations is also planned. We will continue the collaboration with the NEUP project led by Virginia Tech (VT) and Michigan University (MU): will perform NEK-2P analyses of heated bundle boiling experiments performed at VT and develop models of the spacers provided by Westinghouse. The focus of the effort will be on modeling of two-phase boiling flow in fuel pin bundles with realistic spacer geometry; (a) evaluate the effect of spacers on vapor distribution and flow topologies, (b) evaluate the effect of spacers on $\mathrm{CHF}$ and (c) evaluate the effect of CHT in the presence of spacers. 


\section{NOTATION}

$\begin{array}{ll}\mathrm{A} & \text { wall area }\left[\mathrm{m}^{2}\right] \\ \mathrm{C}_{\mathrm{p}} & \text { specific heat }[\mathrm{J} / \mathrm{kg} . \mathrm{K}] \\ \mathrm{d} & \text { diameter }[\mathrm{m}] \\ \mathbf{g} & \text { gravity }\left[\mathrm{m} / \mathrm{s}^{2}\right] \\ \mathrm{h} & \text { enthalpy }[\mathrm{j} / \mathrm{kg}] \\ \mathrm{h}_{\mathrm{fg}} & \text { latent heat of vapor }[\mathrm{J} / \mathrm{kg}] \\ \mathrm{m} & \text { mass }[\mathrm{kg}] \\ \mathbf{q} & \text { heat flux }\left[\mathrm{W} / \mathrm{m}^{2}\right] \\ \mathrm{t} & \text { time }[\mathrm{sec}] \\ \mathrm{T} & \text { temperature }[\mathrm{K}] \\ \mathrm{V} & \text { volume }\left[\mathrm{m}^{3}\right] \\ \alpha & \text { volume fraction } \\ \rho & \text { density }\left[\mathrm{kg} / \mathrm{m}^{3}\right] \\ \boldsymbol{\sigma} & \text { surface tension }[\mathrm{N} / \mathrm{m}] \\ \theta & \text { phase topology }[-] \\ \lambda & \text { thermal conductivity }[\mathrm{W} / \mathrm{m} . \mathrm{K}]\end{array}$

$\begin{array}{ll}\text { Subscripts } \\ \text { b } & \text { bubble } \\ \mathrm{c} & \text { continuous fluid (or) convection } \\ \mathrm{d} & \text { disperse fluid } \\ \mathrm{g} & \text { vapor } \\ \mathrm{L} & \text { liquid } \\ \mathrm{q} & \text { quench } \\ \mathrm{w} & \text { wall } \\ \text { drop } & \text { droplet } \\ \text { dry } & \text { dryout } \\ \text { sat } & \text { saturation } \\ \text { sup } & \text { super heat } \\ \text { vap } & \text { vaporization }\end{array}$

\section{ACKNOWLEDGMENTS}

This work was funded by the U.S Department of Energy, Office of Nuclear Energy, Nuclear Energy Advanced Modeling and Simulation (NEAMS) program, under Argonne contract DEAC02-06CH11357.

We gratefully acknowledge the computing resources provided on Bebop, a high-performance computing cluster operated by the Laboratory Computing Resource Center at Argonne National Laboratory. 


\section{REFERENCES}

1. Fischer et al., Petascale algorithms for reactor hydrodynamics, J. Phys. Conf. Series (2008)

2. Tentner et al., Computational Fluid Dynamics Modeling of Two-phase Flow in a Boiling Water Reactor Fuel Assembly, Proc. Intl. Conf. Mathematics and Computations, American Nuclear Society, Avignon, France, Sept. 2005.

3. Tentner et al., Integral Validation of a CFD Model for the Simulation of Two-Phase Flow Phenomena in a Boiling Water Reactor: Analyses of the BFBT Full Bundle Tests, Nuclear Engineering and Design, June 2009

4. Ustinenko et al., Validation of CFD-BWR, a new two-phase computational fluid dynamics model for boiling water reactor analysis, Nuclear Engineering and design 238 (2008) 660670.

5. Tentner et al., Computational fluid dynamics modeling of two-phase boiling flow and critical heat flux, Proc. Intl. Conference on Nuclear Energy ICONE-22, Prague, 2014.

6. Tentner et al., Modeling of Two-Phase Boiling Flow and Critical Heat Flux with the NEK-2P CFD Code, Proc. Intl. Conference on Nuclear Energy ICONE-25, Shanghai, 2017.

7. Becker et al., An experimental investigation of post-dryout heat transfer, Department of Nuclear Reactor Engineering, Royal Institute of Technology, KTH-NEL-33, Sweden, 1983.

8. Bartolomei et al. Teplomassoobmen-IV, vol. 5. Minsk. ITMO AN BSSR Press, Vol. 5, pp. 38 (1980).

9. Tentner et al., Modeling of two-phase flow in a BWR fuel assembly with a high-fidelity CFD code, NURETH-16, Chicago, 2015.

10. Tentner et al. Advances in computational fluid dynamics modeling of two phase flow in a boiling water reactor fuel assembly", Proc. Int. Conf. Nuclear Engineering ICONE-14, Miami, Florida, USA, July 17-20, 2006.

11. Tentner et al. Development and Validation of an Extended Two-Phase CFD Model for the analysis of Boiling Flow in Reactor Fuel Assemblies", Proc. Int. Conf. Advances in Nuclear Power Plants, Nice, France, May 13-18, 2007.

12. Tentner et al. Computational Fluid Dynamics Modeling of Two-Phase Flow and Inter-Phase Surface Topologies in a BWR Fuel Assembly," Proceedings of ICONE16, the $16^{\text {th }}$ International Conference on Nuclear Engineering, Orlando, FL, USA, May 11-15, 2008.

13. Tomboulides and Orszag, A quasi two-dimensional benchmark problem for low Mach number compressible codes, Journal of Computational Physics, 146, p.691-706, 1998.

14. Tomboulides et al., Numerical simulation of low Mach number reactive flows, Journal of Scientific Computing, 12(2), p.139-167, 1997.

15. Kurul N., Podowski, M., "Multidimensional effects in sub-cooled boiling", Proc. 9th Heat Transfer Conference, Jerusalem (1990). 
16. Tentner et al., Advances in Modeling Critical Heat Flux in LWR Boiling Flows with the NEK-2P CFD Code. 26 ${ }^{\text {th }}$ int. conf. on Nuclear Engineering (ICONE 26), 2018.

17. Hales et al., Bison User Manual. Idaho National Laboratory. INL/MIS-13-30307 (2014).

18. Vegendla., Development and validation of a conjugate heat transfer model for the two-phase CFD code NEK-2P, NURETH-18, Portland, 2019.

19. Liu, Y., $3 \times 3$ Rod bundle boiling loop, Virginia Tech. (not published). 


\section{Argonne}

\section{Nuclear Science and Engineering Division}

Argonne National Laboratory

9700 South Cass Avenue, Bldg. 208

Argonne, IL 60439

www.anl.gov 